\title{
What we already know about rhubarb: a comprehensive review
}

\author{
Hong Xiang ${ }^{1 \dagger}$, Jiaxin Zuo ${ }^{1,2 \dagger}$, Fangyue Guo ${ }^{3 \dagger}$ and Deshi Dong ${ }^{4 *}$
}

\begin{abstract}
Rhubarb (also named Rhei or Dahuang), one of the most ancient and important herbs in traditional Chinese medicine (TCM), belongs to the Rheum L. genus from the Polygonaceae family, and its application can be traced back to 270 BC in "Shen Nong Ben Cao Jing". Rhubarb has long been used as an antibacterial, anti-inflammatory, anti-fibrotic and anticancer medicine in China. However, for a variety of reasons, such as origin, variety and processing methods, there are differences in the effective components of rhubarb, which eventually lead to decreased quality and poor efficacy. Additionally, although some papers have reviewed the relationship between the active ingredients of rhubarb and pharmacologic actions, most studies have concentrated on one or several aspects, although there has been great progress in rhubarb research in recent years. Therefore, this review aims to summarize recent studies on the geographic distribution, taxonomic identification, pharmacology, clinical applications and safety issues related to rhubarb and provide insights into the further development and application of rhubarb in the future.
\end{abstract}

Keywords: Rhubarb, TCMs, Taxonomic identification, Pharmacology, Clinical application

\section{Background}

Rhubarb is one of the most ancient and important herbs with thick roots, hollow and erect stems and small whitegreen or purple-red flowers clustered on the branches [1]. Rhubarb includes approximately 60 species of plants of the genus Rheum L. from the Polygonaceae family [2]. The rhizome of rhubarb was classified as a top medicinal plant, which can be traced back to $270 \mathrm{BC}$ in an ancient Chinese book "Shen Nong Ben Cao Jing" [3]. Rhubarb has mainly been used for medicinal purposes in Asia, but it often refers to a few edible rhubarbs in Europe and the Middle East. Modern studies of rhubarb have identified the chemical constituents [4], pharmacological activities $[5,6]$ and functional mechanisms [7] in a more scientific and rigorous way. Although some papers have reviewed the relationships between the active ingredients

\footnotetext{
*Correspondence: dongdeshi@dmu.edu.cn

${ }^{\dagger}$ Hong Xiang, Jiaxin Zuo and Fangyue Guo contributed same work to this paper and they are the co-first authors

${ }^{4}$ Department of Clinical Pharmacy, First Affiliated Hospital of Dalian Medical University, Dalian, China

Full list of author information is available at the end of the article
}

of rhubarb and pharmacologic actions [2], most of these studies have concentrated on one or several aspects, although research on rhubarb has made great progress in recent years. In this review, we not only summarize the leading-edge understanding in certification methods, quality control, pharmacology and clinical applications of rhubarb but also introduce the geographic distribution, taxonomic identification and toxicity. This review delivers multifaceted and different views and opinions from the field, which will provide insights into the application of rhubarb and be helpful for increasing awareness of the diversity and situations in which the biological resources of rhubarb plants are used.

\section{Global geographic distribution of rhubarb}

According to the database of the Global Biodiversity Information Facility (https://www.gbif.org/), 23 rhubarb species are recorded. As shown in Fig. 1, rhubarb species including $R$. tanguticum Maxim., $R$. officinale Baill., $R$. palmatum L., $R$. acuminatum Hook. f. \& Thomson., $R$. australe D. Don. are mainly distributed in Europe and the southwestern area of China, while $R$. rhabarbarum L. and

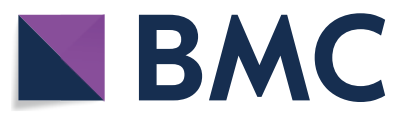

(c) The Author(s) 2020. This article is licensed under a Creative Commons Attribution 4.0 International License, which permits use, sharing, adaptation, distribution and reproduction in any medium or format, as long as you give appropriate credit to the original author(s) and the source, provide a link to the Creative Commons licence, and indicate if changes were made. The images or other third party material in this article are included in the article's Creative Commons licence, unless indicated otherwise in a credit line to the material. If material is not included in the article's Creative Commons licence and your intended use is not permitted by statutory regulation or exceeds the permitted use, you will need to obtain permission directly from the copyright holder. To view a copy of this licence, visit http://creativecommons.org/licenses/by/4.0/. The Creative Commons Public Domain Dedication waiver (http://creativecommons.org/publicdomain/zero/1.0/) applies to the data made available in this article, unless otherwise stated in a credit line to the data. 

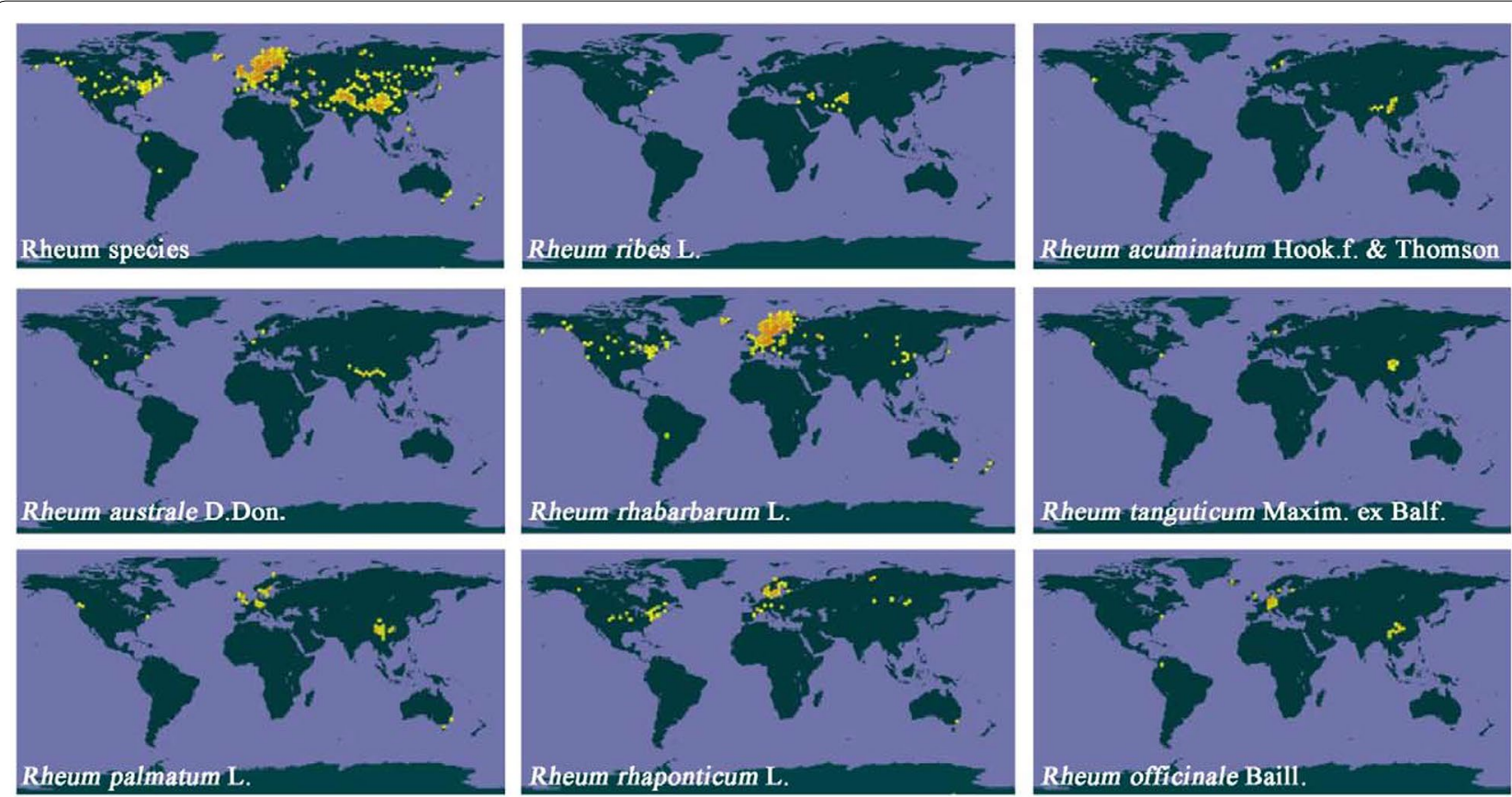

Fig. 1 Geographical distribution of Rhubarb species. Data from the Global Biodiversity Information Facility (https://www.gbif.org/)

R. rhaponticum L. are distributed widely across Europe to North America and part of Asia, showing obviously different geographical distributions. As the distribution center of rhubarb, there are 39 species and 2 varieties in China, most of which are concentrated in northwest and southwest China. $R$. palmatum L. grows in forest margins in mountainous regions of China, such as in the provinces of Sichuan, Gansu, Qinghai and Tibet, and $R$. tanguticum Maxim. and $R$. officinale Baill. grow in welldrained mountainous areas, such as in Hubei, Sichuan, Yunnan and Guizhou Provinces [8]. Three species of Rheum, including $R$. tanguticum Maxim., $R$. officinale Baill. and $R$. palmatum L. have been officially adopted into both the Chinese Pharmacopoeia and Korean Pharmacopoeia using the common drug name "Dahuang". Japanese Pharmacopoeia prescribes the three species together with $R$. coreanum and their interspecific hybrids as origins for medicinal rhubarb [9].

\section{Taxonomic identification}

\section{Traditional and classic methods}

The quality of traditional Chinese medicine (TCM) is closely related to its variety and origin. With the expansion of market demand, rhubarb has been planted in a larger range of areas. Several species similar to rhubarb (such as Rumex crispus, Rumex aquatica and Reynoutria elliptica) are frequently used in medicinal formulations and labeled as rhubarb [9], which often confuses researchers and doctors, and quality degradation that affects therapeutic efficacy has also been pointed out by doctors [8]. Accordingly, much effort has been focused on the taxonomic identification of these various species, and some progress has been made. Traditional methods used to identify rhubarb are mainly based on the characteristics of the flowers, leaves, cross-sections of roots, and crystal characteristics of the powder. The characteristics of the leaves and flowers can be used to identify different species of rhubarb, which was recorded in " $Z h i$ Wu Ming Shi Tu Kao", a Chinese botanical work initially published in 1848, and rhubarb morphology, as the first step of screening, is still widely used in the field detection of species. Rhubarb listed in the Pharmacopoeia comes from the root and stem of $R$. tanguticum Maxim., $R$. officinale Baill. and $R$. palmatum L., while other rhubarb species, including $R$. franzenbachii Münter., $R$. australe D. Don., $R$. nobile Hook.f. \& Thomson. and $R$. wittrockii C.E. Lundstr., are often misused in the treatment of diseases with weak efficacy. Therefore, we describe the characteristic morphology of the above seven rhubarb species in Table 1, which can provide some information for the identification of rhubarb [10]. Briefly, all three kinds of medicinal rhubarb have leaf splits with obviously different depths and shapes, and the other four species of rhubarb have no splits on their leaves with lower heights.

However, it is difficult to correctly identify the exact species due to the similarity between species and morphological variation in the leaves. Therefore, the 10th China Pharmacopoeia Committee introduced and stated 
Table 1 Characteristic morphologies of seven rhubarb species

\begin{tabular}{|c|c|c|c|c|}
\hline Species & Height & Flowers & Leaves shapes & Leaves splits \\
\hline R. tanguticum Maxim. & $1.5-2 \mathrm{~m}$ & Small, purple or light red & $\begin{array}{l}\text { Subcircular or broadly ovate, } \\
30-60 \mathrm{~cm} \text { long, narrow and } \\
\text { pointed apex }\end{array}$ & $\begin{array}{l}\text { About } 5 \text { splits, needle-shaped, } \\
\text { closely to the base of the leaf }\end{array}$ \\
\hline R. officinale Baill. & $1.5-2 \mathrm{~m}$ & Large, yellowish-white & $\begin{array}{l}\text { Subcircular, } 30-50 \mathrm{~cm} \text { in diameter, } \\
\text { pointed apex }\end{array}$ & $\begin{array}{l}\text { Shallow, only } 1 / 5 \text { to } 1 / 4 \text {, } \\
\text { triangular shape }\end{array}$ \\
\hline R. palmatum L. & $1.5-2 \mathrm{~m}$ & Small, purple-red or yellow-white & $\begin{array}{l}\text { Subcircular, } 40-60 \mathrm{~cm} \text { in diameter, } \\
\text { pointed apex }\end{array}$ & About $1 / 3$ to $1 / 4$, triangular shape \\
\hline R. franzenbachii Münter. & $0.5-0.9 \mathrm{~m}$ & Yellow-white, 3-6 clusters & $\begin{array}{l}\text { Cardiac ovate, } 12-22 \mathrm{~cm} \text { long, } \\
10-18 \mathrm{~cm} \text { wide, corrugated } \\
\text { margin }\end{array}$ & Few or no \\
\hline R. australe D. Don. & $0.7-2 \mathrm{~m}$ & Purple-red & $\begin{array}{l}\text { Oval-elliptic, } 20-50 \mathrm{~cm} \text { long, } \\
18-40 \mathrm{~cm} \text { wide, margin with } \\
\text { weak wrinkles }\end{array}$ & Few or no \\
\hline R. nobile Hook.f. \& Thomson. & $1-2 \mathrm{~m}$ & Yellow-green, 5-9 clusters & $\begin{array}{l}\text { Lotus-shaped, } 20-30 \mathrm{~cm} \text { in diam- } \\
\text { eter, round apex }\end{array}$ & Few or no \\
\hline R. wittrockii C.E. Lundstr. & $0.5-1 \mathrm{~m}$ & $\begin{array}{l}\text { White-green, small, } 2 \text { mm in } \\
\text { diameter }\end{array}$ & $\begin{array}{l}\text { Ovate, } 15-26 \mathrm{~cm} \text { long, } 10-20 \mathrm{~cm} \\
\text { wide, obtuse and acute apex, } \\
\text { margin with weak wrinkles }\end{array}$ & Few or no \\
\hline
\end{tabular}

three methods to identify rhubarb: 1) the first two methods are based on their root cross-sectional characteristics and powder crystal morphology; 2) the third method is thin-layer chromatography (TLC), which requires five major orange fluorescent spots on the chromatographic phase at the same location as the control, and exposure to ammonia vapor turns the orange to red.

\section{Modern identification methods}

The information provided by the traditional qualitative methods mentioned above is too little to distinguish plant species with similar appearances or chemical compositions [11]. Rhubarb can be used to treat multiple diseases, which is related to the complex chemical composition caused by plant species, growth environment, harvest time, processing and so on [8]. Therefore, methods that can identify the most components in rhubarb are widely used for species identification and quality identification (Table 2). The major constituents of rhubarb are a variety of phenolic compounds, such as anthraquinone derivatives, dianthrones, stilbenes, polyphenols, flavonoids and chromones. Among them, rhein, emodin, aloeemodin, physcion and chrysophanol are well recognized as biologically active components. Their contents are often used as a criterion for the quality control of rhubarb products. Various methods have been proposed for the quantitative determination of the five major anthraquinones based on high-performance liquid chromatography (HPLC), capillary zone electrophoresis (CZE), micellar electrokinetic chromatography (MEC), TLC and many other methods. Each method has its own advantages, but no summary and comparison exist at present, which is not conducive to the selection of content determination methods. HPLC remains the mainstream analytical method for rhubarb. VanMen et al. developed an HPLC-based method and successfully selected 17 peaks with rhubarb, including 5 pharmacologically active compounds. Ninety-six samples were separated into 5 species based on linear discriminant analysis with an accuracy of $100 \%$ [9]. However, using HPLC alone either provides poor sensitivity or is time consuming due to the variations in rhubarb species and concentrations of these compounds in samples [12]. To improve sensitivity and increase the analysis efficiency, capillary HPLC has been used in quality control analyses of rhubarb [13]; additionally, HPLC coupled with many detectors, such as ultraviolet (UV) [14], diode array detector (DAD) [4], capillary electrophoresis (CE) [15], and mass spectrum (MS) [16], has been developed, which makes it more possible to detect the different components [11]. The fingerprint method for the systematic study of the chemical constituents of TCMs can be used to indicate the chemical characteristics of TCMs by chromatogram or spectrogram. This method has been internationally applied to evaluate the authenticity, goodness and stability of TCMs. Jin et al. successfully established a fingerprint method using high-performance liquid chromatography- photodiode array detection (HPLC-DAD) to control the quality of $R$. tanguticum [4]. This HPLC fingerprint analysis method provides an important reference for the establishment of quality control methods for other rhubarb varieties.

Metabolomic characterization or metabolite profiling has been used to analyze TCMs and screen for bioactive markers. Based on absorption, distribution, metabolism 


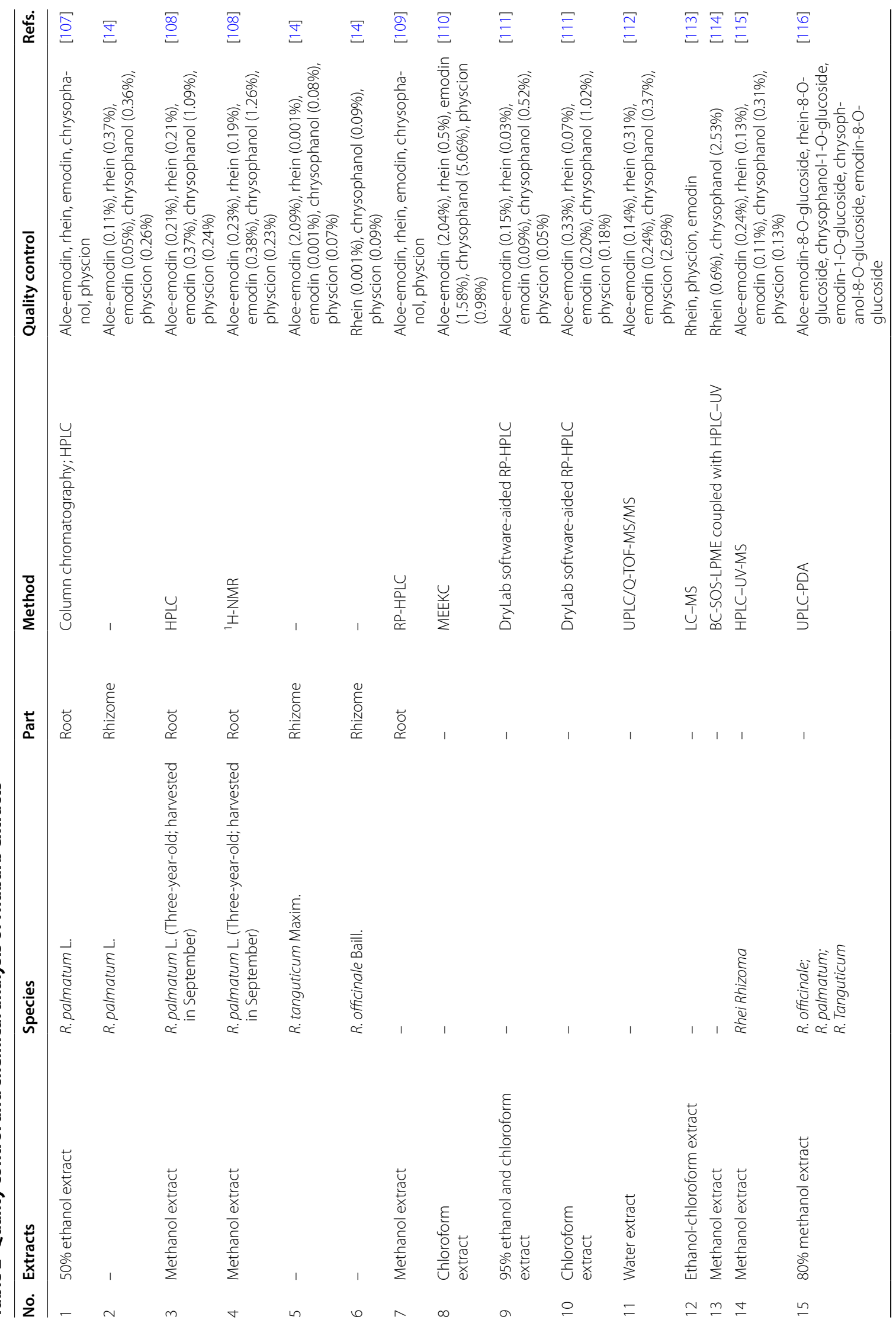




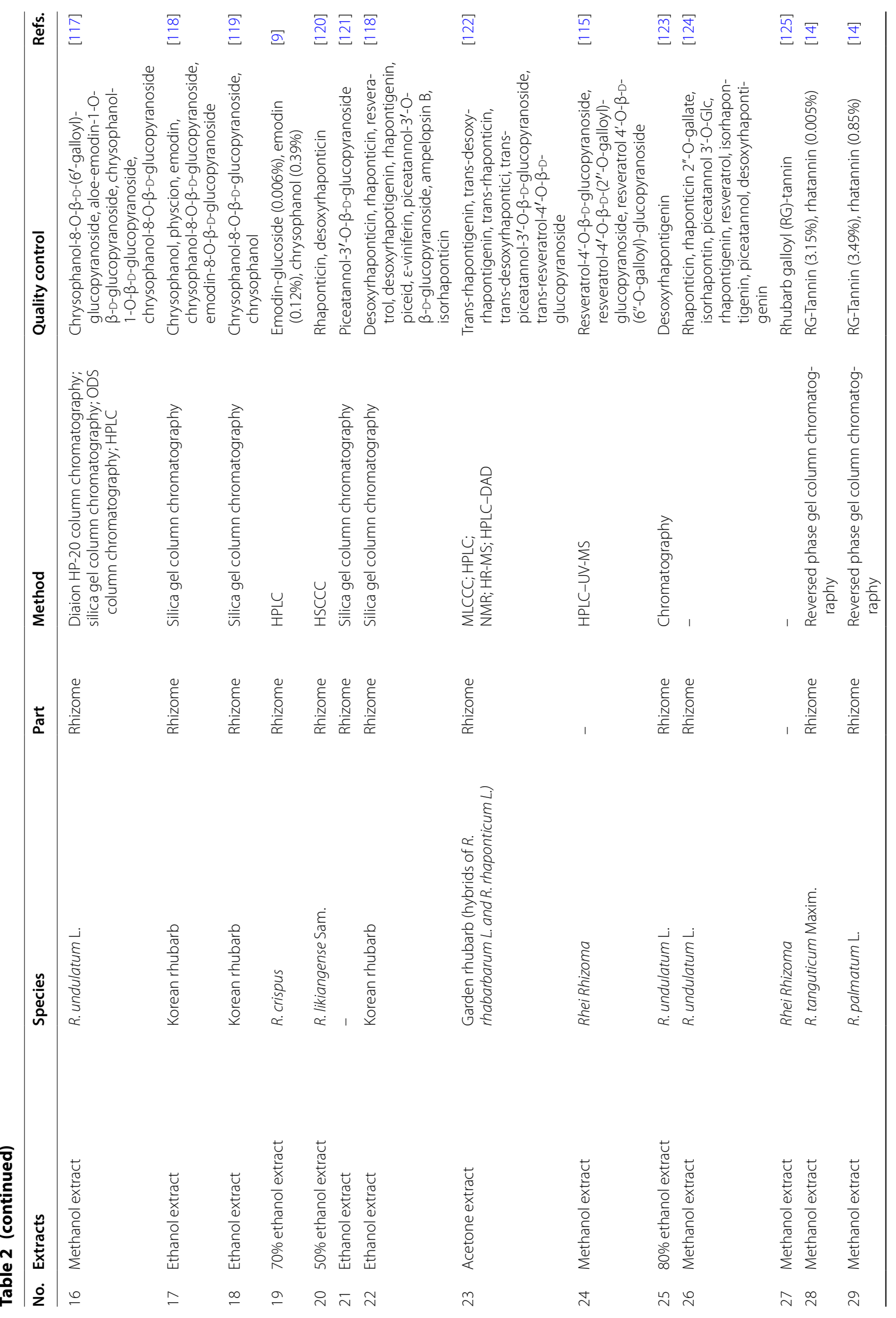




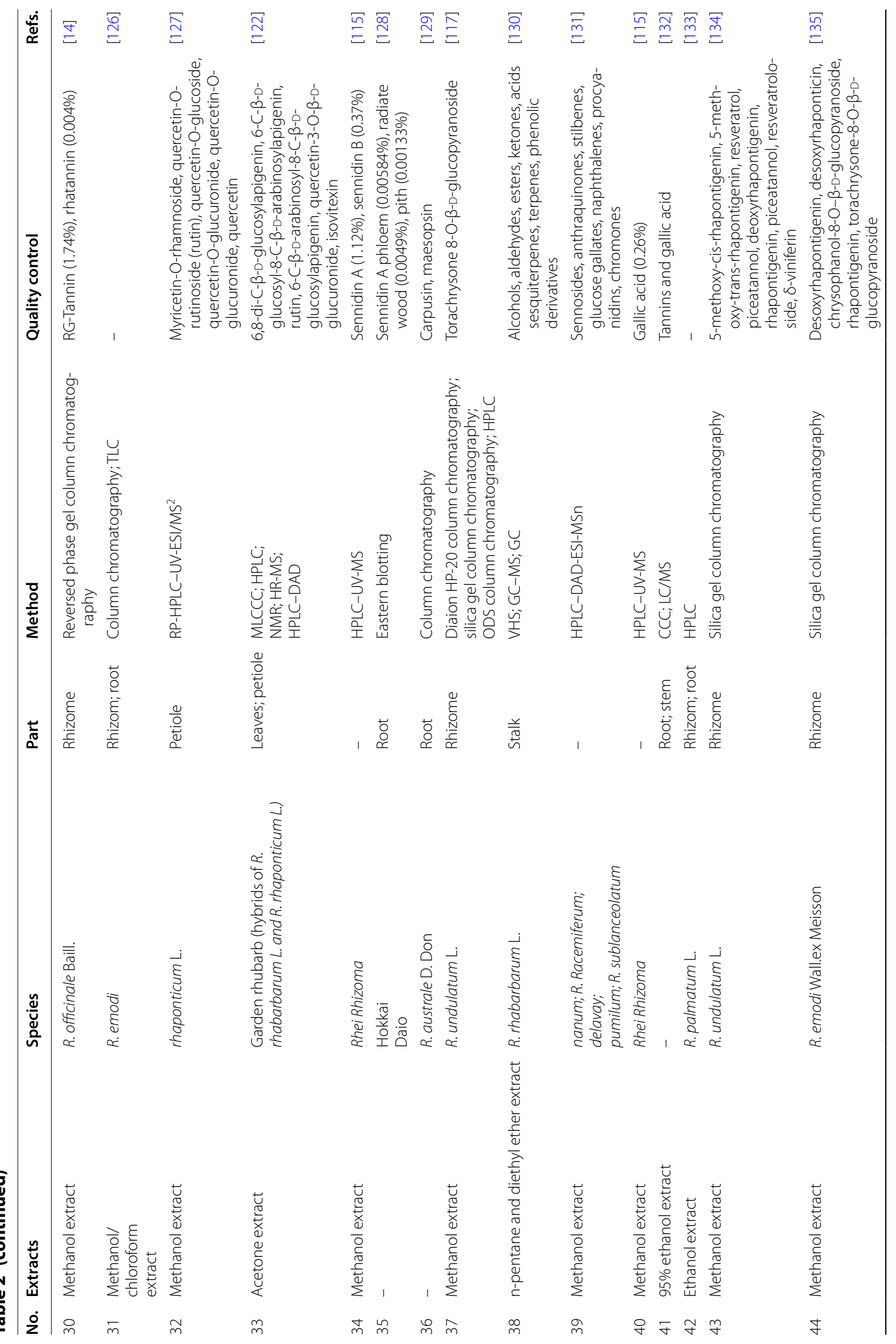




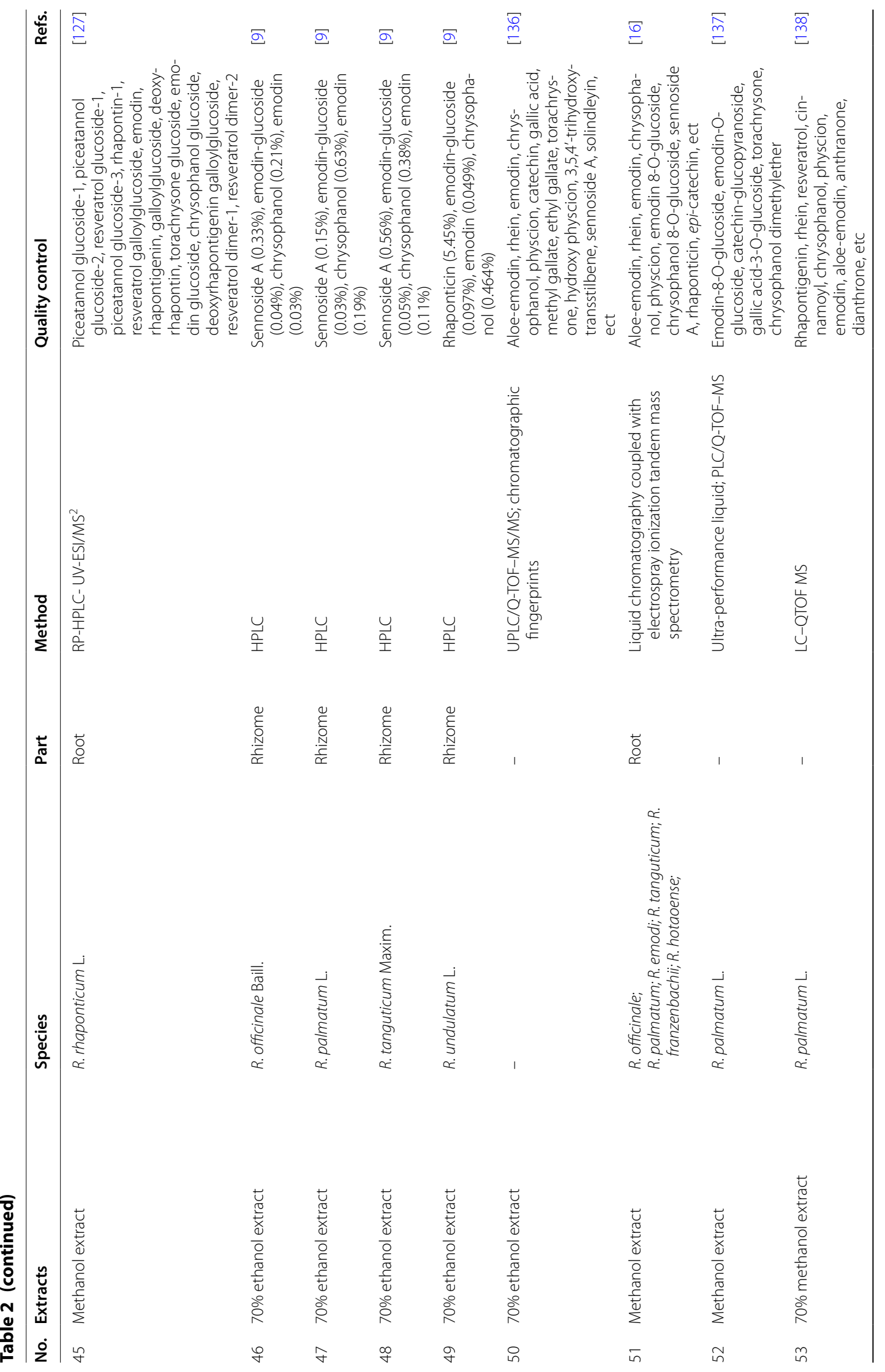







and excretion characteristics, these methods aim to detect representative profiles of metabolites for different species [11]. Tseng et al. developed ultrahigh-pressure LC (UHPLC) methods coupled with UV detectors to characterize the metabolomic profiles of different rhubarb species [13]. It is noteworthy that this method can be used for hybrid rhizome detection due to its high sensitivity and selectivity. Small chemical constituents in herbs originating from hybridization can be clearly observed through similarity measurements of metabolic profiles. Although fingerprint analysis by HPLC and metabolite profiling by chromatographic-mass spectrometric methods have high sensitivity and selectivity, long runtime and expensive instruments limit their broad use. The chloroplast gene sequence can be used as a quality evaluation index of rhubarb, which may indicate the production area of the plants. However, the identification of each species has not been clarified [17].

In conclusion, identification by HPLC coupled with detectors based on the main chemical constituents of rhubarb has become the mainstream method. Chemical fingerprint analysis methods reflect the majority of components in rhubarb, which is one of the most accurate and sensitive identification methods at present and can even reflect the origin of rhubarb. The metabolomic characterization method can identify the hybrid rhizome, and compared with fingerprint analysis by HPLC, the analytical time is shorter. Genomics has been introduced to study TCMs, which may suggest the production areas of plants, but some limitations should be noted: plants growing in neighboring areas have the same or similar mature enzyme gene of the chloroplast genome (matK gene) sequences, so the identification of different species in adjacent areas can be confusing.

\section{Pharmacology}

With the development of a research focus on rhubarb, an increasing number of pharmacological effects have attracted the attention of researchers. The main pharmacological activities of rhubarb include antitumor [18], regulation of gastrointestinal flora [19], protection of the intestinal mucosal barrier [5, 6], anti-inflammatory [20], and inhibition of fibrosis [21]. In addition to emodin and sennoside, which are the main chemical components inhibiting fibrosis and purgation, most of the pharmacological effects are the result of the joint action of several anthraquinones in rhubarb. Figure 2 shows an overview of the pharmacological activities and functional mechanisms of rhubarb.

\section{Regulation of bacterial action}

Rhubarb has efficient antibacterial activities against a variety of bacteria, including Staphylococcus aureus, bifidobacteria, Lactobacillus, Helicobacter pylori, Escherichia coli, methicillin-resistant Staphylococcus aureus and multidrug-resistant Helicobacter pylori [22, 23]. It is noteworthy that rhubarb methanol extract has stronger inhibition of E. coli, Listeria monocytogenes, Klebsiella pneumoniae and Bacillus subtilis than standard antibiotics [24]. Mechanistically, rhubarb can inhibit the growth of Staphylococcus aureus by destroying its bacterial cell wall structure and changing the permeability of the cell membrane [25]. The formation of bacterial biofilms is an important cause of bacterial multidrug resistance. Streptococcus suis is one of the most important swine pathogens and can cause persistent infection in humans. Ding et al. showed that rhubarb can inhibit the formation of biofilms by downregulating transduction systems, influencing the levels of DNA binding protein and transcriptional regulation factors [26]. Similarly, emodin can inhibit the biofilm formation of Pseudomonas aeruginosa and Stenotrophomonas maltophilia [27]. Aloe-emodin can destroy bacterial membranes by the interaction between phosphatidylethanolamine and phosphatidylglycerol [28].

In addition, the effect of rhubarb on the human gut microbiota is complex and diverse. The homeostasis of gut microbiota is conducive to inhibiting the growth of pathogenic bacteria in the intestinal tract [29] and maintaining host energy, metabolic homeostasis, and the immune system $[30,31]$. Zhang et al. pointed out that the number of intestinal Escherichia coli, bifidobacteria and total anaerobes increased after rhubarb was given to critically ill patients [19]. Luo et al. found that TCM prescriptions containing rhubarb increased the number of intestinal Firmicutes and actinomycetes [32]. Moreover, studies have shown that rhubarb could restore the Th17/Treg balance by restoring diversity, significantly increasing the abundance of Firmicutes and Actinobacteria and decreasing Proteobacteria and Bacteroidetes [32,33]. Rhubarb can also improve ulcerative colitis in mice by regulating gut microbiota to restore Th17/Treg balance [32]. In addition, rhubarb can prevent liver inflammation caused by acute alcohol intake [34] and change the content of aromatic amino acids and phenol in feces by regulating gut microbiota [35].

Overall, rhubarb has strong antibacterial activity and a wide antibacterial spectrum, and it can also reverse bacterial resistance to antibiotics by inhibiting the formation of bacterial biofilms. Oral rhubarb has intervention effects on the ecological balance of intestinal flora, thus playing a positive role in inflammation, immunity and other aspects of the body. 


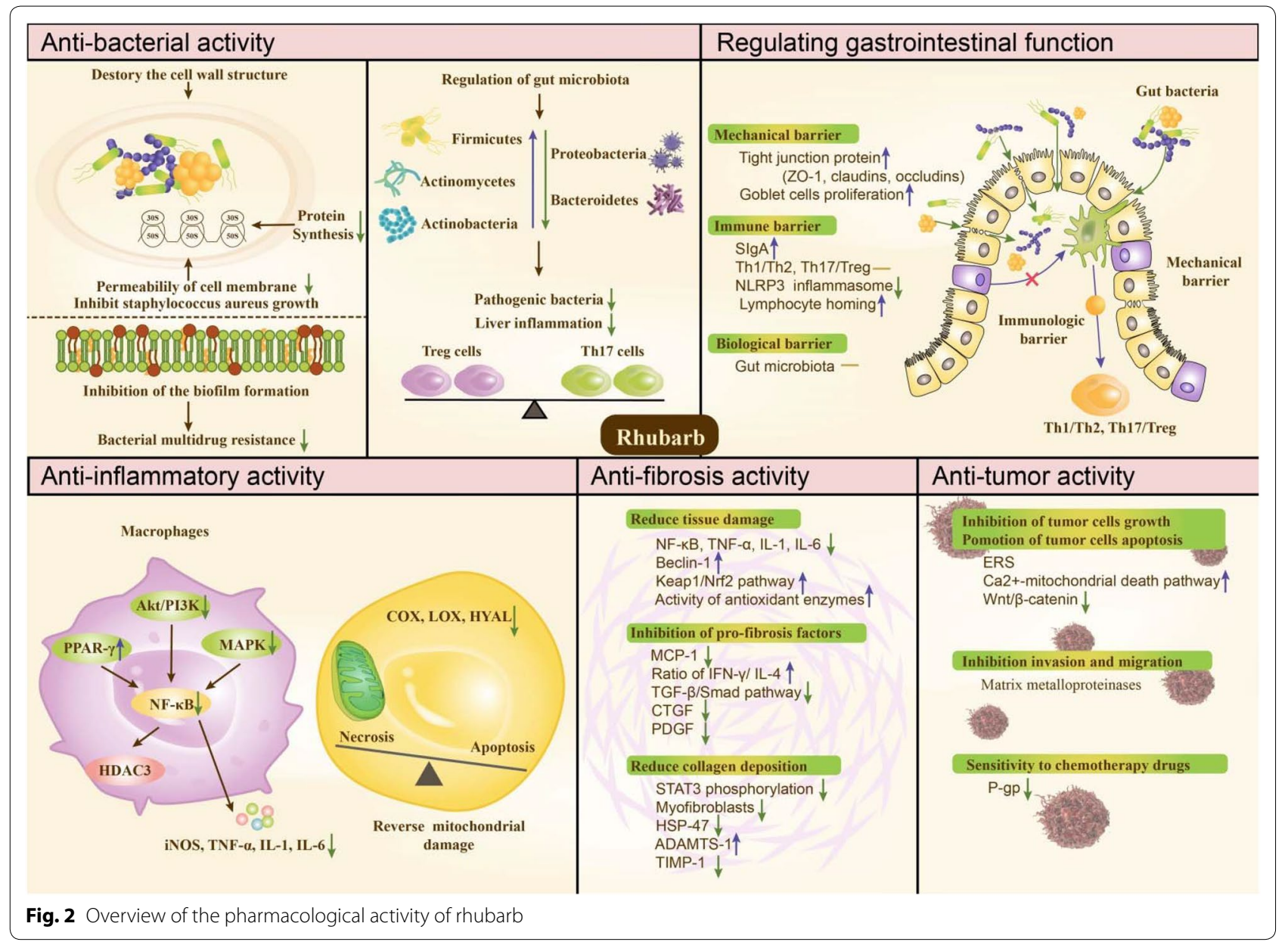

\section{Regulating gastrointestinal function}

The main medicinal effect of rhubarb on the gastrointestinal tract is to promote the digestion of residual food. Anthraquinone compounds in rhubarb, including sennosides, rheinosides and anthraquinone aglyconesa, have efficient laxative effects by promoting intestinal contraction and movement [2]. Furthermore, anthraquinone compounds can stimulate the submucosal nerve plexus, reduce the conductance of $\mathrm{K}^{+}$channels on the cell membrane and enhance the electrical excitability of intestinal smooth muscle cells. In addition, tannins extracted from rhubarb have been proven to play an antidiarrheal role, and the underlying mechanism may be its promotion of protein coagulation [36].

The intestinal mucosal barrier is composed of the epithelial barrier, immune barrier, intestinal flora barrier and chemical barrier [37], which have the function of separating the contents in the intestinal cavity and preventing the invasion of pathogenic antigens [38]. Many clinical and animal experiments have proven that rhubarb could protect the intestinal mucosal barrier, and its mechanism is complex: (1) Rhubarb can maintain the balance of gut microbiota, make the disturbed flora return to normal and prevent the gut microbiota from shifting $[5,6]$. (2) Rhubarb ameliorates mucosal damage through modulating intestinal permeability by increasing the expression of junction proteins [39]. (3) Rhubarb can regulate the immune function of the intestine. Briefly, rhubarb alleviates excessive innate immune- mediated inflammatory responses and intestinal damage by inhibiting the expression of the nucleotide-binding oligomerization domain-like receptor protein 3 (NLRP3) inflammasome [40]. Moreover, rhubarb anthraquinones can increase the expression of secreted immunoglobulin A (SIgA) and restore the balance of Th1/Th2 and Th17/Treg [40, 41]. In addition, rhubarb can regulate intestinal lymphocyte homing, improve the immune function of intestinal mucosa and relieve ulcerative colitis [42]. (4) Rhubarb promotes the proliferation of goblet cells in the intestinal mucosa, which can secrete a large amount of mucus to reinforce the intestinal mucosal barrier by forming a mucosal layer [34]. 
In short, there are a variety of pharmacological effects of rhubarb in the gastrointestinal tract. The combination of anthraquinones in rhubarb play a role in inducing diarrhea, while tannic acid can inhibit the laxative effect of anthraquinones and thereby induce antidiarrheal effects. Moreover, rhubarb can maintain or restore the barrier function of the intestinal mucosa and prevent gut microbiota from shifting. Rhubarb also has the function of regulating gastrointestinal motility disorders $[19,43]$, increasing intestinal blood perfusion [5], clearing gastrointestinal oxygen free radicals, and eliminating inflammatory factors [34].

\section{Anti-inflammatory activity}

In recent years, the underlying mechanisms of the antiinflammatory effects of rhubarb have attracted more attention. Kolodziejczyk-Czepas et al. reviewed the antiinflammatory effects of rhaponticin and the aglycone rhapontigenin and concluded that their anti-inflammatory effects were induced by inhibiting cyclooxygenase (COX), lipoxygenase (LOX) and hyaluronoglucosaminidase (HYAL) activation and modulating a variety of proinflammatory responses [20]. In addition to rhaponticin, various other components of rhubarb have anti-inflammatory effects, such as emodin, rhein, chrysophanol, and aloe emodin.

Wen et al. constructed an inflammation model by stimulating RAW264.7 cells with lipopolysaccharide (LPS) and treated the cells with rhein. These results showed that rhein exerts its anti-inflammatory function by regulating the peroxisome proliferator-activated receptor- $\gamma /$ nuclear factor kappa B/histone deacetylases 3 (PPAR- $\gamma / \mathrm{NF}-\mathrm{kB} /$ HDAC3) axis [44]. Sha et al. demonstrated that rhein ameliorates radiation-induced acute enteritis in vivo through the same pathway [45]. In addition, emodin and chrysophanol could inhibit LPS-induced inflammation in RAW264.7 cells through the PPAR- $\gamma$-dependent pathway $[46,47]$. Hu et al. treated LPS-stimulated RAW264.7 macrophages with aloe-emodin $(5-20 \mu \mathrm{M})$ to investigate the anti-inflammatory effects of aloe-emodin [48]. The results showed that aloe-emodin at $10 \mu \mathrm{M}$ or $20 \mu \mathrm{M}$ exerts anti-inflammatory effects by reducing the activation of NF- $\mathrm{kB}$ via the inhibition of inhibitor of NF- $\mathrm{kB}-\alpha$ $(\mathrm{I} \kappa \mathrm{B} \alpha)$ degradation and mitogen-activated protein kinase (MAPK) phosphorylation. Feng et al. treated acute pancreatitis (AP) rats with rhubarb decoction orally $(150 \mathrm{mg} /$ $\mathrm{kg}$ ) and found that rhubarb probably attenuated AP by inhibiting activation of MAPKs [49]. Our previous studies also proved that emodin alleviated AP via miRNA$30 \mathrm{a}-5 \mathrm{p} / \mathrm{HtrA}$ serine peptidase $1 /$ transforming growth factor- $\beta$ (HTRA1/TGF- $\beta$ ) and purinergic receptor P2X, ligand-gated ion channel, 7/NLRP3 (P2X7/NLRP3) inflammatory signaling $[50,51]$.
In the treatment of inflammatory diseases, rhubarb can promote recovery of the structure and physiological functions of various organs and improve the cure rate and prognosis of patients. For instance, emodin can reduce the degree of acinar necrosis and induce apoptosis in rats with acute necrotizing pancreatitis [52]. In addition, chrysophanol can reverse mitochondrial damage, promote acinar cell proliferation, and reduce the degree of damage to pancreatic tissues [53].

\section{Anti-fibrotic activity}

Fibrosis is the common outcome of chronic liver injury, chronic kidney disease, pulmonary interstitial disease and other chronic diseases. Degeneration and necrosis of parenchymal cells, as the primary causes of fibrosis, can activate macrophages and release active factors. In conditions with active factors, static extracellular matrix (ECM)-producing cells activate into myofibroblasts, which can increase the synthesis of ECM and eventually cause fibrosis [54]. Rhubarb alleviates fibrosis by inhibiting or reversing the necrosis of parenchymal cells, reducing the activation and migration of monocytes to damaged tissues, inhibiting the activation of fibroblasts, relieving collagen deposition, and promoting the degradation of collagen.

The role of the inflammatory response in the development and progression of fibrosis has been recognized. On the one hand, inflammation damages parenchymal cells; on the other hand, it activates corresponding macrophages and releases active factors to promote the occurrence and progression of fibrosis [55]. Tian et al. treated bleomycin-induced pulmonary fibrosis in rats with emodin $(20 \mathrm{mg} / \mathrm{kg})$ and found that emodin protected rats from pulmonary fibrosis by inhibiting the activation of NF- $\mathrm{KB}$ and reducing the expression of proinflammatory factors, such as tumor necrosis factor- $\alpha$ (TNF- $\alpha$ ), interleukin-6 (IL-6) and interleukin-1 $\beta$ (IL1及) [21]. Emodin also inhibits the expression of monocyte chemoattractant protein (MCP-1) to reduce the infiltration of monocyte-derived macrophages into the liver. Cytokines secreted by macrophages and lymphocytes play important roles in the pathogenesis of fibrosis [56]. Reducing the ratio of IFN- $\gamma / \mathrm{IL}-4$ is beneficial to the occurrence and development of pulmonary fibrosis, while increasing the ratio of IFN- $\gamma / \mathrm{IL}-4$ can alleviate pulmonary fibrosis $[57,58]$. Furthermore, emodin can reduce the expression of collagen I ( $\mathrm{Col} \mathrm{I})$, collagen III (Col III) and Beclin 1 and thereby improve the degree of renal fibrosis [59].

TGF- $\beta$ is the most powerful fibrogenic cytokine that can secrete ECM by directly activating a variety of ECMproducing cells and reducing ECM degradation by stimulating the generation of protease inhibitors [60]. The 
Smad protein family includes the most important downstream molecules in the intracellular signaling process of the TGF- $\beta$ superfamily. A recent study has shown that emodin alleviates pulmonary fibrosis by increasing the expression of Smad7 and thereby silencing the TGF- $\beta /$ Smad pathway [61]. Guan et al. found that emodin could inhibit the activation of myofibroblasts by downregulating the phosphorylation of signal transduction and transcriptional activator-3 (STAT3) and further decrease the synthesis of collagen by reducing the expression of heat shock protein-47 (HSP-47) [5, 62]. Similarly, emodin also alleviates renal fibrosis by inhibiting the expression of connective tissue growth factor (CTGF) and plateletderived growth factor (PDGF) and the deposition of Col I and Col III [63]. In addition, emodin can also increase the degradation of Col I and Col III and ECM in lung tissues by upregulating the expression of a disintegrinlike and metalloproteinase with thrombospondin type 1 motif (ADAMTS-1) and downregulating the expression of tissue inhibitor of metalloproteinase-1 (TIMP-1), respectively $[64,65]$. In conclusion, emodin exerts antifibrotic effects by regulating the inflammatory response, oxidative stress, autophagy, and TGF- $\beta$-mediated ECM processes.

\section{Antitumor activity}

Rhubarb has a strong inhibitory effect on a variety of tumors in the digestive, respiratory and reproductive systems, such as human stomach cancer [66], pancreatic cancer [67], nasopharyngeal carcinoma, lung adenocarcinoma [68] and ovarian carcinoma [69]. Rhubarb plays vital roles in multiple biological processes of tumor development through several pathways and targets. It inhibits the growth of tumor cells [18], suppresses tumor invasion and migration $[69,70]$, and even hinders the formation of tumor neovascularization. These antitumor responses may be attributed to a variety of antitumor chemicals extracted from rhubarb, such as emodin, rhein, aloe emodin, and distyrene [2]. A previous study found that rhein could induce human aortic smooth muscle cell apoptosis via a mitochondria-dependent pathway but mediate human nasopharyngeal carcinoma cell apoptosis through an endoplasmic reticulum stress- and $\mathrm{Ca}^{2+-}$ dependent mitochondrial death pathway. In addition, rhein inhibited the migration and invasion of human tongue cancer SCC-4 cells and human ovarian carcinoma SKOV3-PM4 cells by modulating matrix metalloproteinases [69, 70]. These findings suggest that the chemical monomers of rhubarb affect many biological processes related to cancer through multiple pathways. The $\mathrm{Wnt} / \beta$-catenin signaling pathway plays an important role in cell proliferation and invasion in lung cancer, stomach cancer, ovarian cancer and nephroblastoma. Previous studies have shown that rhubarb also inhibits tumor metastasis by promoting the degradation of $\beta$-catenin protein and negatively regulating the Wnt signaling pathway [3]. It is worth mentioning that rhubarb can inhibit the invasion and metastasis of lung cancer, gastric cancer and ovarian cancer. Whether this is related to rhubarb's influence on the Wnt/ $\beta$-catenin signaling pathway remains to be proven.

Compared with traditional cytotoxic drugs, it is very difficult for tumors to develop resistance to rhubarb due to its multiple targets. Interestingly, emodin at a concentration of $10 \mu \mathrm{M}$ can increase the sensitivity of tumor chemotherapy and radiotherapy by decreasing the function of P-glycoprotein (P-gp) and activating the mitochondrial apoptosis pathway in vitro [71, 72]. Although numerous studies have demonstrated that rhubarb can inhibit multiple biological processes and signaling pathways in tumors, few clinical applications have been reported. This may be due to the low cytotoxicity selectivity of rhubarb at high doses. Studies have shown that the monomer components of rhubarb had significant cytotoxicity to human normal liver LO2 cells, HL-7702 cells [73] and human renal tubular epithelial HK-2 cells $[74,75]$ in a dose- and time-dependent manner. Therefore, more attention should be paid to developing targeted agents from rhubarb to reduce the distribution of drugs in noncancerous tissues.

\section{Clinical applications}

Inflammation, infection and oxidative stress are the most common causes of cell damage. Due to its extensive pharmacological effects, rhubarb can interfere with the development of various diseases. The majority of studies have focused on the efficacy of rhubarb on severe acute pancreatitis (SAP) [5, 6], sepsis [7], chronic renal failure (CRF) [8], etc. The results are summarized in Table 3. Most clinical experiments with rhubarb and its active constituents adopt randomized, double-blind and placebo-controlled trials as the study design, and the results have shown that rhubarb could significantly improve feeding tolerance in critically ill patients, intestinal permeability in sepsis patients, oxygenation function in acute respiratory distress syndrome (ARDS) patients, and so on. Specifically, rhubarb has a significant effect on SAP patients. It can effectively relieve abdominal pain, abdominal distension and other symptoms, shorten the ICU and hospital stay of SAP patients by promoting the absorption of pancreatic exudate, improving gastrointestinal function, reducing systemic inflammation and mitigating SAP-related damage to the liver and kidney.

\section{Constipation}

Rhubarb contains a large number of anthraquinone chemical constituents, which have a strong purgatory 







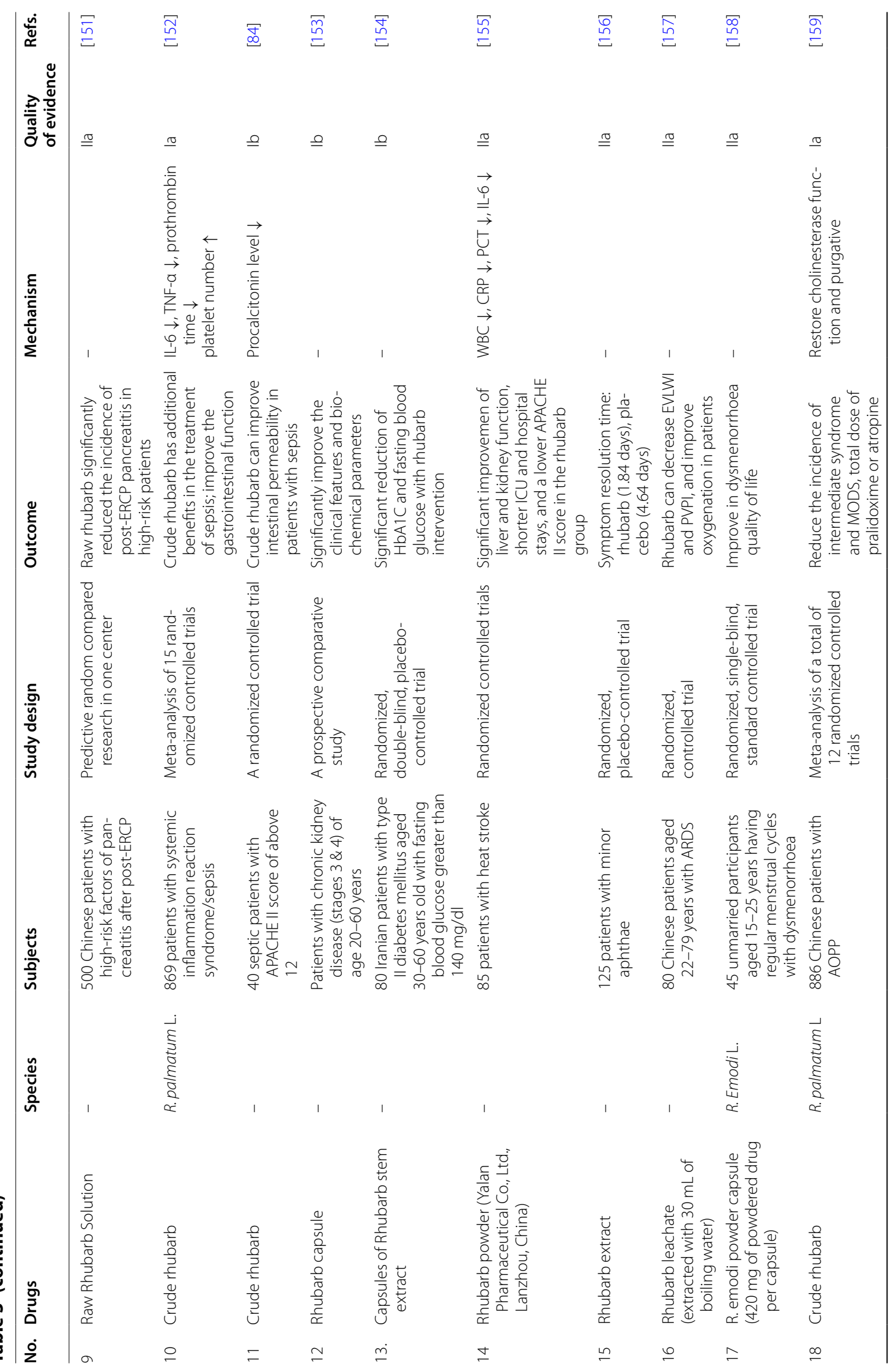




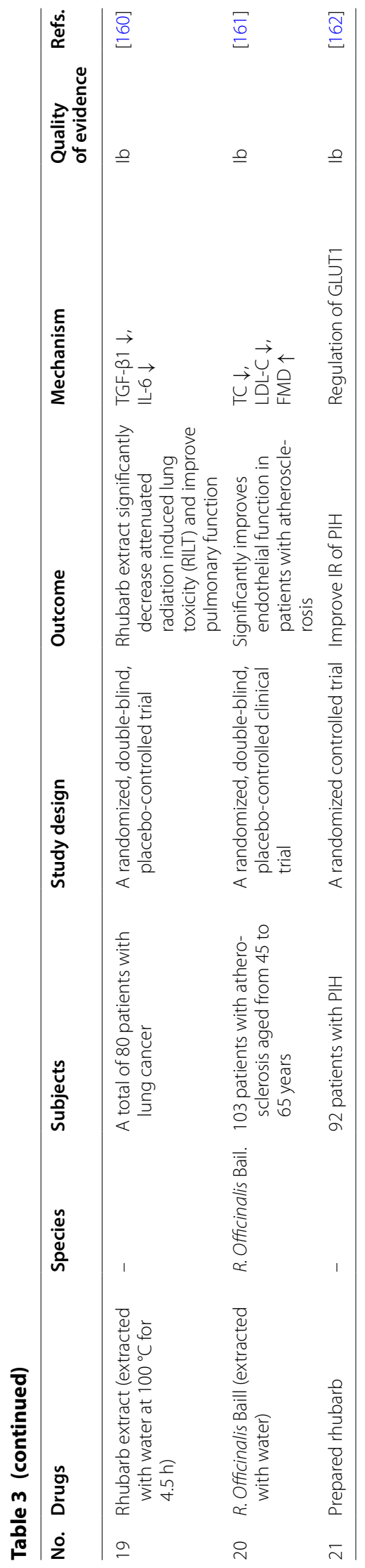


function. Rhubarb powder and peppermint oil are commonly used to treat constipation caused by thoracolumbar fracture [4], type 2 diabetes or acute stroke [76]. A meta-analysis of 850 constipation patients based on 10 randomized controlled trials (RCTs) showed that the regimen was effective in treating constipation, and no serious adverse events were reported in any trial [77].

\section{Severe acute pancreatitis}

SAP is a common clinical acute abdominal disease with a mortality rate as high as $20 \%-30 \%$ [5]. A large number of clinical studies have shown that rhubarb enema can reduce serum inflammatory cytokines, high sensory C-reactive protein (CRP) and endotoxin levels, and relieve the systemic inflammatory stress response and restore intestinal mucosal barrier function in SAP patients [78, 79]. Moreover, applying hot compresses with rhubarb decreases the symptoms of pancreatic leakage in SAP patients [80]. Meanwhile, for SAP patients with gastrointestinal retention and paralysis, nasal injections of rhubarb can also achieve therapeutic effects [81]. In addition, capillary ischemia, blood stasis, microthrombus formation and other microcirculation disorders are common in the early stage of SAP, and rhubarb can reverse the decline in pancreatic blood flow and reduce pancreatic bleeding, which may be related to its antiinflammatory, blood circulation promotion and blood stasis removal effects [49].

Clinically, the combination of rhubarb and the basic treatment for SAP is commonly used to increase the therapeutic effect. Two meta-analyses involving nearly 2000 SAP patients were conducted to evaluate the efficacy and safety of trypsin inhibitors or somatostatin combined with rhubarb in the treatment of SAP, and the results showed that this treatment can significantly reduce hospital stay, mortality and serum amylase levels in SAP patients [5, 6]. Moreover, rhubarb was used in combination with early enteral nutrition [6], highvolume hemofiltration [82], and magnesium sulfate [7]. These combinations significantly decreased the severity and levels of liver and kidney damage in SAP patients by improving gastrointestinal function and decreasing the systemic inflammatory response. Therefore, rhubarb alone or rhubarb combined with the basic treatment of SAP may be safe and effective treatments for patients.

\section{Sepsis}

Sepsis is a systemic inflammatory response syndrome (SIRS) caused by infection, and the gastrointestinal tract is an important target organ for promoting SIRS after infection [83]. Sepsis patients often suffer from immune dysfunction and abnormal coagulation function. A metaanalysis sorting out the treatment information of 869 patients in 15 RCTs showed that rhubarb was effective in the adjuvant treatment of sepsis [7]. Prothrombin time and proinflammatory factor (such as IL- 6 and TNF- $\alpha$ ) levels significantly decreased and platelet count markedly increased after rhubarb administration. However, crude rhubarb treatment did not significantly reduce 28 -day mortality compared to conventional treatment [7]. In addition, patients with SIRS were treated with rhubarb powder by oral administration or nasal feeding for three days, and the results showed that the levels of serum TNF- $\alpha$, CRP and complement 3 (C3) and 4 (C4) dramatically decreased. Another randomized double-blind experiment randomly selected 40 eligible sepsis patients and found that rhubarb can reduce intestinal mucosal permeability in patients with sepsis, thereby reducing bacterial toxin translocation and alleviating symptoms in patients with sepsis $[84,85]$. These results suggest that rhubarb may be used in the clinical treatment of sepsis via its anti-inflammation, anticoagulation, gastrointestinal protection, and bacterial and toxin translocation inhibition effects. In addition, rhubarb can also increase $\mathrm{T}$ cell subsets, which suggests that the regulation of immune function may also contribute to the mechanism of rhubarb in treating sepsis [83].

\section{Chronic renal failure}

The common pathology of CRF is renal fibrosis, which involves the glomerulus and renal interstitium [86]. Rhubarb has unique advantages in improving the early symptoms of CRF and delaying the progression of renal failure [8]. The potential mechanisms include inhibition of renal fibrosis, promotion of toxin excretion, recovery of metabolic disorders, protection of renal cells from excessive inflammation and oxidative stress damage [87]. Rhubarb is mainly administered by retention enema in the treatment of CRF, and the dose should depend on the number of defecation times of the patient per day [88]. Shenkang injection is a kind of TCM that is extracted and refined rhubarb, astragalus, Salvia miltiorrhiza and safflower. A phase IV clinical study included 2200 subjects, and the total effective rate was $73.05 \%$ after Shenkang injection treatment for renal failure [89].

\section{Others}

Oral rhubarb rhizome extract significantly reduced glycosylated hemoglobin, fasting glucose, and body weight in patients with type 2 diabetes [90]. Rhubarb liquid nasal infusion combined with montmorillonite powder and blood purification can rapidly remove the toxins in patients with organophosphorus pesticide poisoning, reduce adverse reactions and shorten the length of stay in the hospital $[91,92]$. Meta-analysis showed that the adjuvant treatment of organic phosphorus pesticide 
poisoning with crude rhubarb could significantly reduce the incidence of intermediate syndrome and multiple organ dysfunction syndrome [64]. Clinical studies have shown that the levels of venous white blood cells (WBCs), CRP, procalcitonin (PCT) and IL-6 in patients with heatstroke were reduced significantly after treatment with rhubarb supplementation $(0.3 \mathrm{~g} / \mathrm{kg}$ body weight) for 3-5 days. Rhubarb can also treat respiratory distress syndrome [93], cholestatic hepatitis [94], hepatic encephalopathy [95], among others.

\section{Safety issue}

Preclinical studies have shown that rhubarb has toxic effects on the liver and kidneys and is associated with cancer risk. Emodin, the main causative agent of rhubarb hepatotoxicity [96], can cause apoptosis in normal human L02 cells and increase the expression of liver injury markers [97]. In addition, emodin can affect the oxidative phosphorylation pathway by inhibiting the activity of all mitochondrial complexes, which causes mitochondrial damage, decreases in mitochondrial membrane potential (MMP), increases in reactive oxygen species (ROS), adenosine triphosphate (ATP) synthesis disorder, and finally liver cell apoptosis [98]. In addition, oral rhubarb or rhubarb products pose a risk of nephrotoxicity due to the abundance of oxalates and anthraquinones, which can lead to deterioration of kidney function as a result of oxalate excretion disorder and crystal deposition in the kidney [99]. However, renal dysfunction due to the above causes has been reported only in children or patients with mild renal disease who have been taking large amounts of rhubarb for a long time [100]. Animal studies have shown that high-dose treatment with rhubarb anthraquinones causes changes in the expression of MAPK kinase 6 and cytochrome P4501A1 (CYP1A1), leading to the swelling and denaturation of renal tubular epithelial cells [101]. It is important to note that the kidney changes were only triggered when the dose was 600 times higher than the clinical dose, suggesting that kidney damage from rhubarb anthraquinone is negligible.

Whether rhubarb has a cancer risk has been controversial for nearly 30 years. A large number of preclinical studies have shown that rhubarb anthraquinones have mutagenic and genotoxic effects [102], and long-term administration of anthraquinone laxatives may damage epithelial cells and induce gastric cancer and colorectal cancer [103]. However, few studies evaluating the possible carcinogenic effects of anthranoid laxatives have been performed in humans [104]. A retrospective analysis of drug use and gastric cancer in 14,616 patients also showed that the use of rhubarb may have little relationship with the development of gastric cancer in practice [105]. In addition, a meta-analysis proposed a relationship between rhubarb anthraquinones and colorectal cancer, but the results have not been examined.

In conclusion, taking rhubarb may damage the health of the liver, and it is recommended to reduce the use of rhubarb in patients with inflammation in the liver due to illness or medication. Long-term use of rhubarb has an effect on liver drug enzyme UDP-glucuronosyltransferase 2B7 (UGT2B7) and transporter multidrug resistance protein 2 (MRP2), so it is necessary to pay attention to the effect on metabolism and excretion of the same drug to prevent adverse effects caused by drug interactions. Patients with kidney disease should carefully avoid long-term use of rhubarb. Whether rhubarb causes cancer remains controversial. Although preclinical studies have shown a carcinogenic risk for rhubarb anthraquinone, the results of animal studies should be carefully generalized to applicability in humans due to the high doses used in animal studies and the relatively long duration of use compared to the animal's lifespan [106].

\section{Conclusion and perspective}

Rhubarb is widely distributed across Europe, North America and part of Asia, and the species from different origins are obviously different. Much effort has been focused on the identification of these various species in recent years. Among them, chemical fingerprint and metabonomic identification methods can reflect the origin and hybrids of rhubarb, respectively. Rhubarb has been used to interfere with the development of various diseases, including SAP, sepsis, and CRF, due to its antibacterial, anti-inflammatory, and antifibrotic activities and the regulation of gastrointestinal function. However, several critical issues need to be considered in future studies. Rhubarb has significant hepatotoxicity, which may be related to the accumulation of emodin in the liver or its influence on the oxidative phosphorylation pathway, and gender may also be a factor affecting its hepatotoxicity. The mechanisms underlying rhubarb hepatotoxicity remains unclear, but understanding the hepatotoxicity is of great value for the clinical promotion of rhubarb. It remains controversial whether long-term use of rhubarb can cause cancer. In addition, the existing literature on the clinical application of rhubarb is mostly based on the experience of doctors and lacks uniform standards. The species and origin of rhubarb used in most of these studies have not been reported, and the cases included in the analyses lack information regarding age, race and other aspects of the participants. More scientific, rigorous and extensive clinical trials are needed to gain insight. 


\begin{abstract}
Abbreviations
TCM: Traditional Chinese medicine; TLC: Thin-layer chromatography; HPLC: High-performance liquid chromatography; CZE: Capillary zone electrophoresis; MEC: Micellar electrokinetic chromatography; UV: Ultraviolet; DAD: Diode array detector; CE: Capillary electrophoresis; MS: Mass spectrum; HPLC-DAD: High-performance liquid chromatography-photodiode array detection; UHPLC: Ultra-high-pressure LC; NLRP3: Nucleotide-binding oligomerization. domain-like receptor protein 3; SIgA: Secreted immunoglobulin A; COX: Cyclooxygenase; LOX: Lipoxygenase; HYAL: Hyaluronoglucosaminidase; LPS: Lipopolysaccharide; PPAR-ү: Peroxisome proliferator-activated receptor- - ; NFKB: Nuclear factor kappa B; HDAC3: Histone deacetylases 3; MAPK: Mitogenactivated protein kinase; AP: Acute pancreatitis; HTRA1: HTRA serine peptidase 1; TGF- $\beta$ : Transforming growth factor- $\beta$; P2X7: Purinergic receptor P2X, ligand-gated ion channel, 7; ECM: Extracellular matrix; TNF-a: Tumor necrosis factor-a; IL-6: Interleukin-6; IL-1 13: Interleukin-1 13; MCP-1: Monocyte chemoattractant protein; IFN-ү: Interferon-ү; IL-4: Interleukin-4; Col I: Collagen I; Col III: Collagen III; STAT3: Signal transduction and transcriptional activator 3; HSP-47: Heat shock protein-47; CTGF: Connective tissue growth factor; PDGF: Plateletderived growth factor; ADAMTS-1: A disintegrin-like and metalloproteinase with thrombospondin type 1 motif; TIMP-1: Tissue inhibitor of metalloproteinase-1; P-gp: P-glycoprotein; SAP: Severe acute pancreatitis; CRF: Chronic renal failure; ARDS: Acute respiratory distress syndrome; RCTs: Randomized controlled trials; CRP: C-reactive protein; SIRS: Systemic inflammatory response syndrome; C3: Complement 3; C4: Complement 4; WBCs: White blood cells; PCT: Procalcitonin; MMP: Mitochondrial membrane potential; ROS: Reactive oxygen species; ATP: Adenosine triphosphate; CYP1A1: Cytochrome P4501A1; UGT2B7: UDP-glucuronosyltransferase 2B7; MRP2: Multidrug resistance protein 2.
\end{abstract}

\section{Acknowledgements}

Not applicable.

\section{Authors' contributions}

$H X$ and $J Z$ conceived this review and drafted the manuscript; FG drew the figures; DD reviewed and approved the submitted manuscript. All authors read and approved the final manuscript.

\section{Funding}

This research was financially supported by the Natural Science Foundation of Liaoning Province (No. 2019-BS-076).

\section{Availability of data and materials}

All data included in this article are available from the corresponding author upon request.

\section{Ethics approval and consent to participate}

Not applicable.

\section{Consent to publish}

We declare that the Publisher has the Author's permission to publish the relevant Contribution.

\section{Competing interests}

The authors declare that they have no competing interests.

\begin{abstract}
Author details
${ }^{1}$ Laboratory of Integrative Medicine, First Affiliated Hospital of Dalian Medical University, Dalian, China. ${ }^{2}$ College of Pharmacy, Dalian Medical University, Dalian, China. ${ }^{3}$ Institute (College) of Integrative Medicine, Dalian Medical University, Dalian, China. ${ }^{4}$ Department of Clinical Pharmacy, First Affiliated Hospital of Dalian Medical University, Dalian, China.
\end{abstract}

Received: 29 May 2020 Accepted: 19 August 2020

Published online: 26 August 2020

\section{References}

1. Lee MR, Hutcheon J, Dukan E, Milne I. Rhubarb (Rheum species): the role of Edinburgh in its cultivation and development. J R Coll Phys Edinburgh. 2017;47(1):102-9.

2. Cao YJ, Pu ZJ, Tang YP, Shen J, Chen YY, Kang A, Zhou GS, Duan JA. Advances in bio-active constituents, pharmacology and clinical applications of rhubarb. Chin Med. 2017;12(1):36-47.

3. Tsai KH, Hsien HH, Chen LM, Ting WJ, Yang YS, Kuo CH, Tsai CH, Tsai FJ, Tsai HJ, Hang CY. Rhubarb inhibits hepatocellular carcinoma cell metastasis via GSK-3- $\beta$ activation to enhance protein degradation and attenuate nuclear translocation of $\beta$-catenin. Food Chem. 2013;138(1):278-85.

4. Jin W, Ge R, Wei Q, Bao T, Shi H, Tu P. Development of high-performance liquid chromatographic fingerprint for the quality control of Rheum tanguticum Maxim. ex Balf. J Chromatogr A. 2006;1132(1-2):320-4.

5. Chen D, Wang L. Mechanisms of therapeutic effects of rhubarb on gut origin sepsis. Chinese Journal of Traumatology. 2009;12(6):365-9.

6. Chen DC, Ma LQ, Liu SZ. Effects of rhubarb on intestinal flora and bacterial translocation in rats with sepsis. Chin Crit Care Med. 2009;21(1):17-20.

7. $\mathrm{PuH}$. Clinical study on the auxiliary therapeutic effect of rhubarb and magnesium sulfate on patients with severe acute pancreatitis. Zhongguo Putong Waike Zazhi. 2009;16(10):1021-2.

8. Tan L, Geng D, Hu F, Dong Q. Rapid Identification and Quantification of Natural Antioxidants in the Seeds of Rhubarb from Different Habitats in China Using Accelerated Solvent Extraction and HPLC-DAD-ESI-MSnDPPH Assay. J Chromatogr Sci. 2016;54(1):48-57.

9. VanMen C, Jang YS, Zhu HM, Lee JH, Trung TN, Ngoc TM, Kim YH, Kang JS. Chemical-based species classification of rhubarb using simultaneous determination of five bioactive substances by HPLC and LDA analysis. Phytochem Anal. 2012;23(4):359-64.

10. Fu KJ, Ohba H. Flora of China. Beijing: Science Press; 2001. p. 8.

11. Jiang Y, David B, Tu P, Barbin Y. Recent analytical approaches in quality control of traditional Chinese medicines - a review. Anal Chim Acta. 2010;657(1):9-18

12. Genovese S, Tammaro F, Menghini L, Carlucci G, Epifano F, Locatelli M. Comparison of three different extraction methods and HPLC determination of the anthraquinones aloe-emodine, emodine, rheine, chrysophanol and physcione in the bark of Rhamnus alpinus L. (Rhamnaceae). Phytochem Analysis. 2010;21(3):261-7.

13. Tseng YJ, Kuo CT, Wang SY, Liao HW, Chen GY, Ku YL, Shao WC, Kuo CH. Metabolomic characterization of rhubarb species by capillary electrophoresis and ultra-high-pressure liquid chromatography. Electrophoresis. 2013;34(19):2918-27.

14. Komatsu K, Nagayama Y, Tanaka K, Ling Y, Basnet P, Meselhy MR. Development of a high performance liquid chromatographic method for systematic quantitative analysis of chemical constituents in Rhubarb. Chem Pharm Bull. 2006;54(7):941-7.

15. Koyama J, Morita I, Kobayashi N. Simultaneous determination of anthraquinones in rhubarb by high-performance liquid chromatography and capillary electrophoresis. J Chromatogr A. 2007;1145(1-2):183-9.

16. Ye M, Han J, Chen H, Zheng J, Guo D. Analysis of phenolic compounds in rhubarbs using liquid chromatography coupled with electrospray ionization mass spectrometry. J Am Soc Mass Spectrom. 2007;18(1):82-91.

17. Yang D, Forsmark CE. Chronic pancreatitis. Curr Opin Gastroen. 2017;33(5):396-403.

18. Zhu YS, Huang Y, Cai LQ, Zhu J, Duan Q, Duan Y, Imperato-McGinley J. The Chinese medicinal herbal formula ZYD88 inhibits cell growth and promotes cell apoptosis in prostatic tumor cells. Oncol Rep. 2003;10:1633-9.

19. Zhang X, Wang L, Chen DC. Effect of Rhubarb on Gastrointestinal Dysfunction in Critically III Patients: a Retrospective Study Based on Propensity Score Matching. Chin Med J. 2018;131(10):1142-50.

20. Kolodziejczyk-Czepas J, Czepas J. Rhaponticin as an anti-inflammatory component of rhubarb: a minireview of the current state of the art and prospects for future research. Phytochem Rev. 2019;18(5):1375-86.

21. Tian SL, Yang Y, Liu XL, Xu QB. Emodin Attenuates bleomycin-induced pulmonary fibrosis via anti-inflammatory and anti-oxidative activities in rats. Med Sci Monitor. 2018;24:1-10.

22. Wang J, Zhao H, Kong W, Jin C, Zhao Y, Qu Y, Xiao X. Microcalorimetric assay on the antimicrobial property of five hydroxyanthraquinone 
derivatives in rhubarb (Rheum palmatum L.) to Bifidobacterium adolescentis. Phytomedicine. 2010;17(8):684-9.

23. Nanasombat S, Kuncharoen N, Ritcharoon B, Sukcharoen P. Antibacterial Activity of Thai medicinal plant extracts against oral and gastrointestinal pathogenic bacteria and prebiotic effect on the growth of Lactobacillus acidophilus. Chiang Mai J Sci. 2018;45(1):33-44.

24. Keser S, Keser F, Karatepe M, Kaygili O, Tekin S, Turkoglu I, Demir E, Yilmaz O, Kirbag S, Sandal S. Bioactive contents, In vitro antiradical, antimicrobial and cytotoxic properties of rhubarb (Rheum ribes L.) extracts. Nat Prod Res. 2019;1:5.

25. Zhou L, Yun BY, Wang YJ, Xie MJ. The antibacterial mechanism of emodin on Staphylococcus aureus. Zhongguo Shengwu Huaxue Yu Fenzi Shengwu Xuebao. 2011;27(12):1156-60.

26. Ding WY, Li YH, Lian H, Ai XY, Zhao YL, Yang YB, Han Q, Liu X, Chen $X Y$, He Z. Sub-Minimum Inhibitory Concentrations of Rhubarb Water Extracts Inhibit Streptococcus suis Biofilm Formation. Front Pharmacol. 2017:8:425-33.

27. Alves DS, Pérez-Fons L, Estepa A, Micol V. Membrane-related effects underlying the biological activity of the anthraquinones emodin and barbaloin. Biochem Pharmacol. 2004;68(3):549-61.

28. Liao J, Zhao L, Yoshioka M, Hinode D, Grenier D. Effects of Japanese traditional herbal medicines (Kampo) on growth and virulence properties of Porphyromonas gingivalis and viability of oral epithelial cells. Pharm Biol. 2013;51(12):1538-44.

29. Ren W, Yin J, Duan J, Liu G, Hardwidge PR. Mouse jejunum innate immune responses altered by enterotoxigenic Escherichia coli (ETEC) infection. Microbes Infect. 2014;16:11.

30. Bin P, Liu S, Chen S, Zeng Z, Huang R, Yin Y, Liu G. The effect of aspartate supplementation on the microbial composition and innate immunity on mice. Amino Acids. 2017;49(12):2045-51.

31. Flint HJ, Scott KP, Louis P, Duncan SH. The role of the gut microbiota in nutrition and health. Nat Rev Gastro Hepat. 2012;9:577-89.

32. Luo $S$, Wen $R$, Wang $Q$, Zhao Z, Nong F, Fu Y, Huang S, Chen J, Zhou L, Luo X. Rhubarb Peony Decoction Ameliorates Ulcerative Colitis in Mice by Regulating Gut Microbiota to Restoring Th17/Treg Balance. J Ethnopharmacol. 2019;231:39-49.

33. Sharma R, Tiku AB. Emodin inhibits splenocyte proliferation and inflammation by modulating cytokine responses in a mouse model system. J Immunotoxicol. 2015;13(1):20-6.

34. Neyrinck AM, Etxeberria U, Taminiau B, Daube G, Hul MV, Everard A, Cani PD, Bindels LB, Delzenne NM. Rhubarb extract prevents hepatic inflammation induced by acute alcohol intake, an effect related to the modulation of the gut microbiota. Mol Nutr Food Res. 2017;61:1-12.

35. Yin S, Guo P, Hai D, Xu L, Shu J, Zhang W, Khan MI, Kurland IJ, Qiu Y, Liu Y. Optimization of GC/TOF MS analysis conditions for assessing host-gut microbiota metabolic interactions: chinese rhubarb alters fecal aromatic Amino acids and phenol metabolism. Anal Chim Acta. 2017;995:21-33.

36. Qin Y, Wang JB, Kong WJ, Zhao YL, Yang HY, Dai CM, Fang F, Zhang L, Li $B C$, Jin C, Xiao XH. The diarrhoeogenic and antidiarrhoeal bidirectional effects of rhubarb and its potential mechanism. J Ethnopharmacol. 2011;133(3):1096-102.

37. Ding LA, Li JS, Li YS, Zhu NT, Liu FN, Tan L. Intestinal barrier damage caused by trauma and lipopolysaccharide. World J Gastroenterol. 2004:10(16):2373-8

38. Vaishnavi C. Translocation of gut flora and its role in sepsis. Indian J Med Microbi. 2013;31(4):334-42.

39. Wang L, Cui YL, Zhang Z, Lin ZF, Chen DC. Rhubarb Monomers Protect Intestinal Mucosal Barrier in Sepsis via Junction Proteins. Chin Med J. 2017:130(10):1218-25.

40. Xiong Y, Chen L, Fan L, Wang L, Zhou Y, Qin D, Sun Q, Wu J, Cao S. Free Total Rhubarb Anthraquinones Protect Intestinal Injury via Regulation of the Intestinal Immune Response in a Rat Model of Severe Acute Pancreatitis. Front Pharmacol. 2018:9:75-88.

41. Diebel LN, Liberati DM, Dulchavsky SA, Diglio CA, Brown WJ. Enterocyte apoptosis and barrier function are modulated by SlgA after exposure to bacteria and hypoxia/reoxygenation. Surgery. 2003;134(4):574-81.

42. Li D, Liu H, Wang E, Tang F. Effect of rhubarb polysaccharide combined with semen crotonis pulveratum on intestinal lymphocyte homing in rats with TNBS-induced colitis. Int J Clin Exp Med. 2018;11(12):13308-18.
43. Shimizu K, Kageyama M, Ogura H, Yamada T, Shimazu T. Effects of Rhubarb on Intestinal Dysmotility in Critically III Patients. Internal Med. 2018:57(4):507-10.

44. Wen Q, Miao J, Lau N, Zhang C, Ye P, Du S, Mei L, Weng H, Xu Q, Liu X, Chen D, Zhang F, Li C, Li H. Rhein attenuates lipopolysaccharide-primed inflammation through NF-KB inhibition in RAW 264.7 cells: targeting the PPARY signal pathway. Can J Physiol Pharm. 2019:1-32.

45. Sha H, Gu Y, Shen W, Zhang L, Qian F, Zhao Y, Li H, Zhang T, Lu W. Rheinic acid ameliorates radiation-induced acute enteritis in rats through PPAR- $\gamma /$ NF-KB. Genes Genom. 2019;41 (8):909-17.

46. Zhu T, Zhang W, Feng SJ, Yu HP. Emodin suppresses LPS-induced inflammation in RAW2647 cells through a PPARY-dependent pathway. Int Immunopharmacol. 2016;34:16-24.

47. Wen Q, Mei L, Ye S, Liu X, Xu Q, Miao J, Du S, Chen D, Li C, Li H. Chrysophanol demonstrates anti-inflammatory properties in LPS-primed RAW 264.7 macrophages through activating PPAR- $\gamma$. Int Immunopharmacol. 2018;56:90-7.

48. Hu B, Zhang H, Meng X, Wang F, Wang P. Aloe-emodin from rhubarb (Rheum rhabarbarum) inhibits lipopolysaccharide-induced inflammatory responses in RAW264.7 macrophages. J Ethnopharmacol. 2014;153(3):846-53.

49. Feng Z, Fei J, Wenjian X, Jiachen J, Beina J, Zhonghua C, Xiangyi $Y$, Shaoying W. Rhubarb attenuates the severity of acute necrotizing pancreatitis by inhibiting MAPKs in rats. Immunotherapy. 2012;4(12):1817-21.

50. Xiang H, Tao X, Xia S, Qu J, Song H, Liu J, Dong S. Emodin Alleviates Sodium Taurocholate-Induced Pancreatic Acinar Cell Injury via MicroRNA-30a-5p-Mediated Inhibition of High-Temperature Requirement A/Transforming Growth Factor Beta 1 Inflammatory Signaling. Front Immunol. 2017;8:1488-502.

51. Zhang Q, Hu F, Guo F, Zhou Q, Xiang H, Shang D. Emodin attenuates adenosine triphosphate-induced pancreatic ductal cell injury in vitro via the inhibition of the P2X7/NLRP3 signaling pathway. Oncol Rep. 2019;42:1589-97.

52. Yuan Y, Gong Z, Lou K, Tu S, Di Z, Xu J. Effects and mechanisms of somatostatin analogs on apoptosis of pancreatic acinar cells in acute pancreatitis in mice. J Gastroen Hepatol. 2001;16(6):683-8.

53. Zhao J, Li G, Xiong W, Liu L, Xiang J, Tang M, Yuan Z. Protective Effects of Rhubarb in Rats with Acute Pancreatitis and the Role of Its Active Compound Rhein on Mitochondria of Exocrine Cells. Evid-Based Compl Alt. 2018;2018:1-9.

54. Gao Z, Wang C. Emodin and organ fibrosis. Chin J Integr Trad West Med. 2005;25(11):1030-2.

55. Bruscia EM, Zhang PX, Ferreira E, Caputo C, Emerson JW, Tuck D, Krause DS, Egan ME. Macrophages directly contribute to the exaggerated inflammatory response in cystic fibrosis transmembrane conductance regulator $^{-1-}$ mice. Am J Resp Cell Mol. 2009;40(3):295-304.

56. Wynn T, Barron L. Macrophages: master regulators of inflammation and fibrosis. Semin Liver Dis. 2010;30(03):245-57.

57. Fusiak T, Smaldone GC, Condos R. Pulmonary Fibrosis Treated with Inhaled Interferon-gamma (IFN- $\gamma$ ). J Aerosol Med Pulm D. 2015;28(5):406-10.

58. Xiong S, Guo R, Yang Z, Xu L, Du L, Li R, Xiao F, Wang Q, Zhu M, Pan X. Treg depletion attenuates irradiation-induced pulmonary fibrosis by reducing fibrocyte accumulation, inducing Th17 response, and shifting IFN-Y, IL-12/IL-4, IL-5 balance. Immunobiology. 2015;220(11):1284-91.

59. Dou F, Ding $Y$, Yao M, Jian $Y$, Wang $W$, Zhao $X$, Wang J, Wen AD. Effect of emodin on fibrosis factor of HK- 2 cells stimulated by TGF- $\beta 1$ through activation of autophagy. Chin Pharmacol Bull. 2018;34(11):1555-9.

60. Dong $\mathrm{H}$, Slain D, Cheng J, Ma W, Liang W. Eighteen cases of liver injury following ingestion of Polygonum multiflorum. Compl Ther Med. 2014;22(1):70-4.

61. Darby IA, Hewitson TD. Fibroblast differentiation in wound healing and fibrosis. Int Rev Cytol. 2007;257:143-79.

62. Guan R, Zhao X, Wang X, Song N, Guo Y, Yan X, Jiang L, Cheng W, Shen L. Emodin alleviates bleomycin-induced pulmonary fibrosis in rats. Toxicol Lett. 2016;262:161-72.

63. Imanishi Y, Maeda N, Otogawa K, Seki S, Matsui H, Kawada N, Arakawa T. Herb medicine Inchin-ko-to (TJ-135) regulates PDGF-BB-dependent signaling pathways of hepatic stellate cells in primary culture and 
attenuates development of liver fibrosis induced by thioacetamide administration in rats. J Hepatol. 2004;41 (2):242-50.

64. Liu L, Qian H, Xiao H, He J, Xie M, Wang Z, Long X. Emodin alleviates pulmonary fibrosis through inactivation of TGF-B1/ADAMTS-1 signaling pathway in rats. Xi Bao Yu Fen Zi Mian Yi Xue Za Zhi. 2016;32(10):1342-6.

65. Gui M, Zhang YF, Xiao ZY, Sun P, Dai JF, Wang SF, Rui YC, Zhang JP. Inhibitory effect of emodin on tissue inhibitor of metalloproteinases-1 (TIMP-1) expression in rat hepatic stellate cells. Digest Dis Sci. 2007:52(1):200-7.

66. Hibasami H, Takagi K, Ishii T, Tsujikawa M, Imai N, Honda I. Induction of apoptosis by rhapontin having stilbene moiety, a component of rhubarb (Rheum officinale Baillon) in human stomach cancer KATO II cells. Oncol Rep. 2007;18(2):347-51.

67. Pan FP, Zhou HK, Bu HQ, Chen ZQ, Zhang H, Xu LP, Tang J, Yu QJ, Chu YQ Pan J, Fei Y, Lin SZ, Liu DL, Chen L. Emodin enhances the demethylation by 5-Aza-CdR of pancreatic cancer cell tumor-suppressor genes P16, RASSF1A and ppENK. Oncol Rep. 2016;35(4):1941-9.

68. Shia CS, Suresh G, Hou YC, Chao PDL, Juang SH. Suppression on metastasis by rhubarb through modulation on MMP-2 and uPA in human A549 lung adenocarcinoma: an ex vivo approach. Mol Nutr Food Res. 2011;133:2.

69. Zhou G, Peng F, Zhong Y, Chen Y, Tang M, Li D. Rhein suppresses matrix metalloproteinase production by regulating the Rac1/ROS/MAPK/AP-1 pathway in human ovarian carcinoma cells. Int J Oncol. 2017;50:933-41.

70. Chen YY, Chiang SY, Lin JG, Ma YS, Liao CL, Weng SW, Lai TY, Chung JG. Emodin, aloe-emodin and rhein inhibit migration and invasion in human tongue cancer SCC-4 cells through the inhibition of gene expression of matrix metalloproteinase-9. Int J Oncol. 2010;36(5):1113-20

71. Liu DL, Bu H, Li H, Chen H, Guo HC, Wang ZH, Tong HF, Ni ZL, Liu HB, $\mathrm{Lin} S \mathrm{SZ}$. Emodin reverses gemcitabine resistance in pancreatic cancer cells via the mitochondrial apoptosis pathway in vitro. Int J Oncol. 2012:40:1049-57.

72. Garg AK, BuchholzTA, Aggarwal BB. Chemosensitization and Radiosensitization of Tumors by Plant Polyphenols. Antioxid Redox Sign. 2005;7(11):1630-47.

73. Koramagazi A, Wang D, Yousef B, Guerram M, Yu F. Rhein triggers apoptosis via induction of endoplasmic reticulum stress, caspase-4 and intracellular calcium in primary human hepatic HL-7702 cells. Biochem Bioph Res Co. 2016;473(1):230-6.

74. Wang C, Wu X, Chen M, Duan W, Sun L, Yan M, Zhang L. Emodin induces apoptosis through caspase 3-dependent pathway in HK-2 cells. Toxicology. 2007;231(2):120-8.

75. Wang C, Jiang Z, Yao J, Wu X, Sun L, Liu C, Duan W, Yan M, Sun L, Liu J, Zhang L. Participation of cathepsin B in emodin-induced apoptosis in HK-2 Cells. Toxicol Lett. 2008;181(3):196-204.

76. Jiang $X$, Wan $Y$. Effects of endocrimology umbilicus compress with rhubarb on constipation in type 2 diabetes mellitus patients. Nursing of Integrated Traditional Chinese and Western Medicine. 2015;1 (2):105-6.

77. Sun Y, Chen X, Wang Y. Meta analysis of umbilical area applying with rhubarb in treatment of constipation. Chinese Nursing Research. 2016:30(11B):4020-4.

78. Liang $M$, Zhang $G$, Jian R. Research progress on rhubarb retention enema in treatment of acute pancreatitis patients. Chinese Nursing Research. 2016;30(6B):2053-6

79. Yao P, Cui M, Li Y, Deng Y, Wu H. Effects of rhubarb on intestinal flora and toll-like receptors of intestinal mucosa in rats with severe acute pancreatitis. Pancreas. 2015;44(5):799-804

80. Wang Y, Zhang X, Li C. Applying Hot compresses with rhubarb and mirabilite to reduce pancreatic leakage occurrence in the treatment of severe acute pancreatitis. Iran J Public Health. 2017:46(1):136-8.

81. Yang $L X, L i u J$, Xing Y, Du LC, Chen J, Hao JY. Treating moderately severe acute pancreatitis with raw rhubarbs by intranasal jejuna injection: a randomized clinical analysis. Chin J Integr Trad West Med. 2017:37(3):306-9.

82. Zou ZD, Wang L, Jiang SB, Wang Y. Early treatment with high-volume hemofiltration combined with rhubarb for patients with severe acute pancreatitis. Acad J Sec Milit Med Univ. 2009;30(4):428-31.
83. Yin C, Guo H. Effect of gavage of rhubarb preparation on immune function in patients with sepsis. Med J Chin Peoples Liber Army. 2016:40(12):1011-4.

84. Fang XL, Fang Q, Luo JJ, Zheng X. Effects of crude rhubarb on intestinal permeability in septic patients. Am J Chin Med. 2007;35(06):929-36.

85. Fang XL, Fang Q, Luo JJ. Effects of raw rhubarb on plasma D-lactate and procalcitonin expressions in patients with sepsis. Chin J Integr Trad West Med. 2006;26(2):128-30.

86. Liu Y. Cellular and molecular mechanisms of renal fibrosis. Nat Rev Nephrol. 2011;7(12):684-96.

87. Zhu W, Wang XM. Progress in study on mechanisms of rhubarb in treating chronic renal failure. Chin J Integr Trad West Med. 2005;25(5):471-5.

88. Kang Z, Bi Z, Ji W, Zhao C, Xie Y. Observation of therapeutic effect in 50 cases of chronic renal failure treated with rhubarb and adjuvant drugs. J Tradit Chin Med. 1993;13(4):249-52.

89. Wang A, Fang H, Wang Y, Tian L, Zhang K, Tang W, Peng P, Dai L, Yang Y. Effect of Shenkang Injection as an Adjunctive Treatment on Early Diabetic Nephropathy and on Patient's Oxidative Stress. Chinese Journal of Experimental Traditional Medical Formulae. 2013;8:308-10.

90. Shojaei-Shad F, Jahantigh-Haghighi M, Mansouri A, Jahantigh-Haghighi $M$. The effect of Rhubarb stem extract on blood pressure and weight of type 2 diabetic patients. Med Sci. 2019;23(96):159-62.

91. Zhu J, Chen C, Yan X, Xiao L, Huang M. Effect of rhubarb and Glauber's salt cathartic intervention on acute organophosphorus pesticide poisoning. Chinese Critical Care Medicine. 2012;24(6):346-8.

92. Yu HJ, Shen DF, Liu B, Shi YC. The observations of curative efficacy of rhubarb combined with blood purification on treatment patients with severe acute organophosphorus pesticide poisoning. Zhonghua Lao Dong Wei Sheng Zhi Ye Bing Za Zhi. 2012;30(4):304-6.

93. Song RX, Dong CM, Zhang HS, Zhang H, Yang ZH, Feng F, Qi Y. Clinical evaluation of compound rhubarb preparation treating acute respiratory distress syndrome patients in plateau areas. Chinese Critical Care Medicine. 2012;24(7):434-5.

94. Huang Z, Ye S, Dong Y, Ye W. Clinical Observations on treatment of infantile cholestatic hepatitis syndrome by Rhubarb. Chi J Integr Med. 1998:4(1):22-4

95. Zhang N, Zhou S, Xiao X, Wang Z, Bai Y, He T, Zhou C, Wang Y, Kun Z, Wang Z, Liu B, Prokop LJ, Hernandez MC, Li J, Gong M. Rhubarb-based Chinese herbal formulae for hepatic encephalopathy: a systematic review and Meta-analysis. J Tradit Chin Med. 2017:37(6):721-34.

96. Li YX, Gong XH, Liu MC, Peng C, Li P, Wang YT. Investigation of liver injury of Polygonum multiflorum Thunb. in rats by metabolomics and traditional approaches. Front Pharmacol. 2017;8:791-801.

97. Lin L, Lin H, Zhang M, Ni B, Yin X, Qu C, Ni J. A novel method to analyze hepatotoxic components in Polygonum multiflorum using ultraperformance liquid chromatography-quadrupole time-of-flight mass spectrometry. J Hazard Mater. 2015;299:249-59.

98. Lin L, LiU Y, Fu S, Qu C, Li H, Ni J. Inhibition of mitochondrial complex function-the hepatotoxicity mechanism of emodin based on quantitative proteomic analyses. Cells. 2019;8(3):263-79.

99. Barceloux DG. Rhubarb and Oxalosis (Rheum Species). Dis Mon. 2009;55(6):403-11.

100. Albersmeyer M, Hilge R, Schröttle A, Weiss M, Sitter T, Vielhauer V. Acute kidney injury after ingestion of rhubarb: secondary oxalate nephropathy in a patient with type 1 diabetes. BMC Nephrol. 2012;13(1):141-5.

101. Yan M, Zhang LY, Sun LX, Jiang ZZ, Xiao XH. Nephrotoxicity study of total rhubarb anthraquinones on Sprague Dawley rats using DNA microarrays. J Ethnopharmacol. 2006;107:308-11.

102. Kawai K, Mori H, Sugie S, Yoshimi N, Inoue T, Nakamaru T, Nozawa Y, Matsushima T. Genotoxicity in the hepatocyte/DNA repair test and toxicity to liver mitochondria of 1-hydroxyanthraquinone and several dihydroxyanthraquinones. Cell Biol Toxicol. 1986;2(4):457-67.

103. Wolfle D, Schmutte C, Westendorf J, Marquardt H. Hydroxyanthraquinones as tumor promoters: enhancement of malignant transformation of $\mathrm{C} 3 \mathrm{H}$ mouse fibroblasts and growth stimulation of primary rat hepatocytes. Cancer Res. 1990:50(20):6540-4.

104. van Gorkom BA, de Vries EG, Karrenbeld A, Kleibeuker JH. Review article: anthranoid laxatives and their potential carcinogenic effects. Aliment Pharmacol Ther. 1999;13(4):443-52. 
105. Mantani N, Sekiya N, Sakai S, Kogure T, Shimada Y, Terasawa K. Rhubarb use in patients treated with Kampo medicines-a risk for gastric cancer. Yakugaku Zasshi. 2002;122(6):403-5.

106. Tu C, Gao D, Li XF, Li CY, Li RS, Zhao YL, Li N, Jia GLC, Pang JY, Cui HR, Ma ZJ, Xiao XH, Wang JB. Inflammatory stress potentiates emodin-induced liver injury in rats. Front Pharmacol. 2015;6:233.

107. Wang CC, Huang YJ, Chen LG, Lee LT, Yang LL. Inducible nitric oxide synthase inhibitors of Chinese herbs III, Rheum palmatum. Planta Med. 2002;68(10):869-74

108. Wang ZW, Wang JS, Yang MH, Luo JG, Kong LY. Developmental changes in the composition of five anthraquinones from rheum palmatum as quantified by 1H-NMR. Phytochem Analysis. 2013;24(4):329-35.

109. He D, Chen B, Tian Q, Yao S. Simultaneous determination of five anthraquinones in medicinal plants and pharmaceutical preparations by HPLC with fluorescence detection. J Pharmaceut Biomed. 2009;49(4):1123-7.

110. Li G, Hu Z. Separation and identification of active components in the extract of Rheum natural products by microemulsion electrokinetic chromatography. Analyst. 1998;123(7):1501-5.

111. Liu CL, Zhu PL, Liu MC. Computer-aided development of a highperformance liquid chromatographic method for the determination of hydroxyanthraquinone derivatives in Chinese herb medicine rhubarb. J Chromatogr A. 1999;857(1-2):167-74.

112. Cao W, Yi L, Ye LH, Cao J, Hu SS, Xu JJ, Peng LQ, Zhu QY, Zhang QY. Application of a highly sensitive magnetic solid phase extraction for phytochemical compounds in medicinal plant and biological fluids by ultra-high performance liquid chromatography coupled with quadrupole time-of-flight tandem mass spectrometry. Electropharesis. 2015;36(19):2404-12.

113. Yuan JF, Ji HH, Qiu ZJ, Wang DH. ECV304/C6 coculture model of the BBB coupled with LC-MS analysis for drug screening from Rhubarb extract(Article). Med Chem Res. 2016;25(9):1935-44.

114. Chen X, Li ZY, Ge X, Hu S, Wang RQ, Yang L, Yu ZH, Bai XH. Ballpoint connector-protected salt-oil-salt liquid phase microextraction for concentration and enrichment of trace anthraquinone compounds in rhubarb(Article). J Sep Sci. 2019:42(13):2231-8.

115. Lin CC, Wu Cl, Lin TC, Sheu SJ. Determination of 19 rhubarb constituents by high-performance liquid chromatography-ultraviolet-mass spectrometry. J Sep Sci. 2006;29:2584-93.

116. Wang Z, Ma P, Xu L, He C, Peng Y, Xiao P. Evaluation of the content variation of anthraquinone glycosides in rhubarb by UPLC-PDA. Chem Cent J. 2013;7(1):1-11.

117. Matsuda H, Morikawa T, Toguchida I, Park J, Harima S, Yoshikawa M. Antioxidant constituents from rhubarb: structural requirements of stilbenes for the activity and structures of two new anthraquinone glucosides. Bioorgan Med Chem. 2001;9(1):41-50.

118. Ngoc TM, Minh PTH, Hung TM, Thuong PT, Lee I, Min BS, Bae K. Lipoxygenase inhibitory constituents from rhubarb. Arch Pharm Res. 2008;31(5):598-605

119. Lee MS, Sohn CB. Anti-diabetic Properties of Chrysophanol and Its Glucoside from Rhubarb Rhizome. Biol Pharm Bull. 2008;31(11):2154-7.

120. Wang $X$, Wang H, Ding C, Suo Y. One-step preparative separation of two polyhydroxystilbenes from Rheum likiangense Sam by high-speed counter-current chromatography. Phytochem Analysis. 2012;23(6):684-8.

121. Woo A, Min B, Ryoo S. Piceatannol-3'-O- $\beta$-D-glucopyranoside as an active component of rhubarb activates endothelial nitric oxide synthase through inhibition of arginase activity(Article). Exp Mol Med. 2010;42(7):524-32.

122. Krafczyk N, Kötke M, Lehnert N, Glomb MA. Phenolic composition of rhubarb. Eur Food Res Technol. 2008;228(2):187-96

123. Choi SZ, Lee SO, Jang KU, Chung SH, Park SH, Kang HC, Yang EY, Cho $\mathrm{HJ}$, Lee KR. Antidiabetic stilbene and anthraquinone derivatives from Rheum undulatum. Arch Pharm Res. 2005;28(9):1027-30.

124. Matsuda H, Tewtrakul S, Morikawa T, Yoshikawa M. Anti-allergic activity of stilbenes from Korean rhubarb (Rheum undulatum L.): structure requirements for inhibition of antigen-induced degranulation and their effects on the release of TNF-alpha and IL-4 in RBL-2H3 cells. Bioorgan Med Chem. 2004;12(18):4871-6.

125. Oi H, Matsuura D, Miyake M, Ueno M, Takai I, Yamamoto T, Kubo M, Moss J, Noda M. Identification in traditional herbal medications and confirmation by synthesis of factors that inhibit cholera toxin-induced fluid accumulation. P Natl Acad Sci USA. 2002;99(5):3042-6.

126. Akhtar MS, Habib A, Ali A, Bashir S. Isolation, identification, and in vivo evaluation of flavonoid fractions of chloroform/methanol extracts of Rheum emodi roots for their hepatoprotective activity in Wistar rats. Int J Nutr Pharmacol Neurol Dis. 2016;6(1):28-34.

127. Pssa T, Raudsepp P, Kuzina K, Raal A. Polyphenolic composition of roots and petioles of Rheum rhaponticum L. Phytochem Analysis. 2009;20(2):98-103.

128. Morinaga O, Uto T, Sakamoto S, Putalun W, Lhieochaiphant S, Tanaka H, Shoyama Y. Development of eastern blotting technique for sennoside $A$ and sennoside $B$ using anti-sennoside $A$ and anti-Sennoside $B$ monoclonal antibodies. Phytochem Analy. 2009;20(2):154-8.

129. Krenn L, Presser A, Pradhan R, Bahr B, Paper DH, Mayer KK, Kopp B. Sulfemodin 8-O-b-D-glucoside, a new sulfated anthraquinone glycoside, and antioxidant phenolic compounds from Rheum emodi. J Nat Prod. 2003;66:1107-9.

130. Dregus M, Engel KH. Volatile Constituents of Uncooked Rhubarb (Rheum rhabarbarum L.) Stalks. J Agr food chem. 2003;51(22):6530-6.

131. Han J, Ye M, Xu M, Qiao X, Chen H, Wang B, Zheng J, Guo DA. Comparison of phenolic compounds of rhubarbs in the section deserticola with Rheum palmatum by HPLC-DAD-ESI-MSn. Planta Med. 2008;74(8):873-9.

132. Hu R, Lu Y, Dai X. Screening of antioxidant phenolic compounds in Chinese Rhubarb combining fast counter-current chromatography fractionation and liquid chromatography/mass spectrometry analysis. J Sep Sci. 2010;33(11):1595-603.

133. Xiong HR, Shen YY, Lu L, Hou W, Luo F, Xiao H, Yang ZQ. The Inhibitory Effect of Rheum palmatum Against Coxsackievirus $B_{3}$ in Vitro and in Vivo. Am J Chin Med. 2012;40(4):801-12.

134. Ha MT, Park DH, Shrestha S, Kim M, Kim JA, Woo MH, Choi JS, Min BS. PTP1B inhibitory activity and molecular docking analysis of stilbene derivatives from the rhizomes of Rheum undulatum L. Fitoterapia. 2018;131:119-26.

135. SureshBabu K, Tiwari AK, Srinivas PV, Ali AZ, Raju BC, Rao JM. Yeast and mammalian a-glucosidase inhibitory constituents from Himalayan rhubarb Rheum emodi Wall.ex Meisson. Bioorg Med Chem Lett. 2004;14(14):3841-5.

136. Yang DZ, Sun G, Zhang AH, Fu S, Liu JH. Screening and analyzing the potential bioactive components from rhubarb, using a multivariate data processing approach and ultra-high performance liquid chromatography coupled with time-of-flight mass spectrometry. Anal Methods. 2015;7(2):650-61.

137. Wang Z, Wang D, Zheng S, Wu L, Huang L, Chen S. Ultra-performance liquid chromatography-quadrupoleltime-of- flight mass spectrometry with multivariate statistical analysis for exploring potential chemical markers to distinguish between raw and processed Rheum palmatum. BMC Complem Altern M. 2014;14(302):1-10.

138. Liu Y, Li L, Xiao YQ, Yao JQ, Li PY, Yu DR, Ma YL. Global metabolite profiling and diagnostic ion filtering strategy by LC-QTOF MS for rapid identification of raw and processed pieces of Rheum palmatum L. Food Chem. 2016;192:531-40.

139. Nizioł J, Sekuła J, Ruman T. Visualizing spatial distribution of small molecules in the rhubarb stalk (Rheum rhabarbarum) by surface-transfer mass spectrometry imaging. Phytochemistry. 2017;139:72-80.

140. Sun J, Wu Y, Dong S, Li X, Gao W. Quantitative studies of rhubarb using quantitative analysis of multicomponents by single marker and response surface methodology(Article). J Sep Sci. 2017:40(19):3792-800.

141. Wang Q, Lu Z, Zhang L, Zhang Q, Wang M, Zhao H, Liu Y, Fu S, Huang Z, Xie Z, Yu H, Zhang Z, Gao X. Applying characteristic fragment filtering for rapid detection and identification of ingredients in rhubarb by HPLC coupled with linear ion trap-Orbitrap mass spectrometry(Article). J Sep Sci. 2017:40(14):2854-62.

142. Gao LL, Guo T, Xu XD, Yang JS. Rapid identification and simultaneous analysis of multiple constituents from Rheum tanguticum Maxim. ex Balf by UPLC/Q-TOF-MS. Nat Prod Res. 2017;31(13):1529-35.

143. Chen A, Sun L, Yuan H, Wu A, Lu J, Ma S. Simultaneous qualitative and quantitative analysis of 11 active compounds in rhubarb using two reference substances by UHPLC. J Sep Sci. 2018;41(19):3686-96. 
144. Sun J, Wu Y, Dong S. Influence of the drying method on the bioactive compounds and pharmacological activities of rhubarb. J Sci Food Agr. 2018;98(9):3551-62.

145. Wan B, Zhang H, Yin J, Fu H, Chen Y, Yang L, Liu D, Lv T, Song Y. Rhubarb vs Glycerin enema for treatment of critically ill patients with intraabdominal hypertension(Article). Exp Ther Med. 2017;14(1):855-61.

146. Li J, Gu Y, Zhou R. Rhubarb to facilitate placement of nasojejunal feeding tubes in patients in the intensive care unit(Article). Nutr Clin Pract. 2016:31(1):105-10.

147. Khiveh A, Hashempur MH, Shakiba M, Lotfi MH, Shakeri A, Kazemeini S, Mousavi Z, Jabbari M, Kamalinejad M, Emtiazy M. Effects of rhubarb (Rheum ribes L.) syrup on dysenteric diarrhea in children: a randomized, double-blind, placebo-controlled trial. J Integr Med. 2017;15(5):365-72.

148. Hu J, Li P, Zhang T. Rhubarb combined with trypsin inhibitor for severe acute pancreatitis: a systematic review and meta-analysis. Phytother Res. 2018;32(8):1450-8.

149. Wan B, Fu H, Yin J. Efficacy of rhubarb combined with early enteral nutrition for the treatment of severe acute pancreatitis: a randomized controlled trial. Scand J Gastroentero. 2014;49(11):1375-84.

150. Zhou Y, Wang L, Huang X, Li H, Xiong Y. Add-on effect of crude rhubarb to somatostatin for acute pancreatitis: a meta-analysis of randomized controlled trials. J Ethnopharmacol. 2016;194:495-505.

151. Wang C, Li Q, Ye P, Zeng S, Li GH, Chen YX, Zhou XJ, Lv NH. Value of Raw Rhubarb Solution in the Precaution of Post-endoscopic Retrograde Cholangiopancreatography Pancreatitis in Patients with High-Risk Factors: a Predictive Random Compared Research in One Center. Digest Dis Sci. 2017;62(4):1043-50.

152. Zhang L, Chen J, Jiang D, Zhang P. Adjuvant treatment with crude rhubarb for patients with systemic inflammation reaction syndrome/ sepsis: a meta-analysis of randomized controlled trials. J Crit Care. 2015;30(2):282-9.

153. Khan IA, Nasiruddin M, Haque SF, Khan RA. Evaluation of Rhubarb Supplementation in Stages 3 and 4 of Chronic Kidney Disease: A Randomized Clinical Trial. Int J Chron Dis. 2014;2014.

154. Shad FS, Haghighi MJ. Study of the effect of the essential oil (extract) of rhubarb stem (shoot) on glycosylated hemoglobin and fasting blood glucose levels in patients with type II diabetes. BioMedicine. 2018:8(4):18-22.

155. Wan Y, Sun SS, Fu HY, Xu YK, Liu Q, Yin JT, Wan B. Adjuvant rhubarb alleviates organs dysfunction and inhibits inflammation in heat stroke(Article). Exp Ther Med. 2018;16(2):1493-8.

156. Rodriguez-Archilla A, Raissouni T. Randomized clinical trial of the effectiveness of complementary therapies for recurrent aphthous stomatitis. Med Clin. 2017;149(2):55-60.

157. He J, Si X, Ji M, Huang J, Zheng W, Wang J, Wang J, Zhu L. Effect of rhubarb on extravascular lung water in patients with acute respiratory distress syndrome. Rev Assoc Med Bras. 2017;63(5):435-40.

158. Rehman H, Begum W, Anjum F, Tabasum H, Zahid S. Effect of rhubarb (Rheum emodi) in primary dysmenorrhoea: a single-blind randomized controlled trial(Article). Journal of Complementary and Integrative Medicine. 2015;12(1):61-9.

159. Wang L, Pan S. Adjuvant treatment with crude rhubarb for patients with acute organophosphorus pesticide poisoning: A meta-analysis of randomized controlled trials. Complement Ther Med. 2015;23(6):794-801.

160. Yu HM, Liu YF, Cheng YF, Hu LK, Hou M. Effects of rhubarb extract on radiation induced lung toxicity via decreasing transforming growth factor-beta- 1 and interleukin- 6 in lung cancer patients treated with radiotherapy. Lung cancer. 2008;59:219-26.

161. Liu YF, Yu HM, Zhang C, Yan F, Liu Y, Zhang Y, Zhang M, Zhao YX. Treatment with Rhubarb Improves Brachial Artery Endothelial Function in Patients with Atherosclerosis: a Randomized, Double-Blind, PlaceboControlled Clinical Trial. Am J Chinese Med. 2007;35(4):583-95.

162. Wang Z, Shi S, Song H. Effect of prepared rhubarb on insulin resistance in patients with pregnancy induced hypertension. Chinese Jouranl of Integrative Medicine. 2003;9(1):35-8.

\section{Publisher's Note}

Springer Nature remains neutral with regard to jurisdictional claims in published maps and institutional affiliations.
Ready to submit your research? Choose BMC and benefit from:

- fast, convenient online submission

- thorough peer review by experienced researchers in your field

- rapid publication on acceptance

- support for research data, including large and complex data types

- gold Open Access which fosters wider collaboration and increased citations

- maximum visibility for your research: over $100 \mathrm{M}$ website views per year

At BMC, research is always in progress.

Learn more biomedcentral.com/submissions 